\title{
Prices and Unit Labor Costs: A New Test of Price Stickiness
}

\author{
Argia M. SBOrdone*广 \\ Rutgers University \\ October 1998 \\ (first draft: December 1997)
}

\begin{abstract}
This paper investigates the predictions of a simple optimizing model of nominal price rigidity for the aggregate price level and the dynamics of inflation. I compare the model's predictions with those of a perfectly competitive, flexible price 'benchmark' model (corresponding to the model of pricing assumed in standard real business cycle models), and evaluate how much the introduction of nominal rigidities improves the model's fit with the data.

The model's predictions are derived using only the firms optimal pricing problem; taking as given the paths of nominal labor compensation, labor productivity, and output, I determine the implied path of prices predicted by the model. Because prices are not a stationary series, I present my results in terms of the predicted path of the price/unit labor cost ratio, where the parameters characterizing such paths are chosen to maximize the fit with the data.

I find that while the evolution of prices relative to unit labor costs is quite different from what would be predicted by the flexible-price 'benchmark' model, a simple model of nominal price rigidity delivers an extremely close approximation both of the price/unit labor cost ratio and of the inflation series, even under a very simple approach to the measurement of marginal costs.
\end{abstract}

\footnotetext{
${ }^{*}$ Correspondence: Department of Economics, Rutgers University, 75 Hamilton Street, New Brunswick, NJ, 08901-1248; ph.(732)-932-8271; e-mail:sbordone@econ.rutgers.edu.

†I thank Mike Woodford for his invaluable advice; Mark Bils, Olivier Blanchard, Jordi Gali, Mark Gertler, Julio Rotemberg, and seminar participants at Princeton University, the NBER Monetary Economics program meeting of April 1998, and the NBER 1998 Summer Institute for helpul comments, and the Institute for International Economic Studies of Stockholm University for its hospitality when I started to work on this project.
} 


\section{Introduction}

This paper investigates the predictions for the aggregate price level and the dynamics of inflation of a simple model of optimal price-setting. The model incorporates nominal price rigidity, either in the form of convex costs of changing prices, as in the version proposed by Rotemberg $(1982,1995)$, or of delays between price adjustments, as in the version proposed by Calvo (1983). I study how much the model's deviations from the assumptions of a 'benchmark' model with flexible prices (corresponding to the model of pricing assumed in standard real business cycle models) improve the fit with the U.S. data.

The failure of prices to move as much as costs over the business cycle has been recently emphasized as a key element in accounting for the fluctuations in output and employment (Rotemberg-Woodford 1991,1998). For example, insofar as price/cost margins move countercyclically, demand shocks may play an important role in aggregate fluctuations, without this having to imply strongly countercyclical real wage changes of a kind that we do not observe. Nominal price rigidities in particular, insofar as they are important, create an obvious channel through which purely nominal disturbances may have real effects.

Following the lead of the RBC literature, the evaluation of models of price determination alternative to the benchmark model have mostly been conducted within a similar framework of general equilibrium models. Several papers consider the extent to which a fully specified quantitative general equilibrium model (including a complete specification of the stochastic properties of all random shocks affecting the economy) can account for various properties of aggregate time series. For example, King and Watson (1996) study, among other things, whether a stylized general equilibrium model with sticky prices, subject to both nominal and real shocks whose stochastic processes are calibrated on data of the US economy, is able to generate a price process with statistical properties (shape of the spectrum, sign and size of dynamic correlation with output) close to those of the actual data. Rotemberg (1995) studies whether a general equilibrium model with costs of adjusting prices delivers the same kind of correlation between predictable components of hours, output and prices, that can be estimated from an unrestricted VAR fitted to U.S. time series.

The approach that these papers, and others in the same spirit, take to comparing the implications of models with nominal rigidities with data on prices and quantities, inevitably involve a very large number of maintained hypotheses about the structure of the economy - for example, very specific assumptions about household preferences, about demographics, about wage-setting, about households' access to credit, and about how households' budgets and other constraints are affected by government policy - in addition to the assumed model of pricing and supply behavior by firms. Since many of these assumptions are highly debatable (for example, the Euler equations implied by a representative household model have been rejected by numerous econometric studies), it is unclear to what extent the failure of a given complete model's predictions to match U.S. data indicate misspecification of the model of pricing, or of some other aspect of the model entirely.

Other evidence on price stickyness is sought in papers that compare theoretical and estimated responses to a particular kind of exogenous shock. For example, Christiano, 
Eichenbaum and Evans (1997) compare the predicted effects of an exogenous tightening of monetary policy in two models of the monetary transmission mechanism, that differ (among other respects) in their assumptions about price flexibility. Rotemberg and Woodford (1997) use a model with nominal rigidity, parametrized so that the model's predicted response to monetary policy shocks matches the dynamic response estimated in the data, to simulate the consequences of alternative monetary policy rules. In these cases, the predictions of the models that are tested not only depend upon the joint specification of household and firm behavior, and of the nature of competition in several different markets, but are also sensitive to the validity of the assumptions used to identify particular exogenous disturbances in the data.

The approach that I propose here differs from these kinds of exercises in several respects. First, the model that is tested is not as ambitious; I do not specify a complete general equilibrium model of the economy, but instead test implications that depend only upon the firm's optimal pricing problem. In such a way I still have to make assumptions about market structure and production costs, but I can more easily understand the effect of each assumption on the results.

Second, rather than specifying the stochastic properties of the ultimate sources of randomness in the economy, I instead take as given the evolution of a number of state variables, and determine what path of prices is predicted by the evolution of these other variables, under the model of price determination considered. In this way I do not need to specify the source of the shock that determines deviations from a steady state equilibrium; the obvious advantage of proceeding in this way is that the results I obtain do not depend on some (more or less) arbitrary identification procedure to extract structural shocks from the residuals of an estimated time series model.

Finally, my "testing" procedure is not based on the econometric estimation of the Euler equations implied by the specific model considered, but is instead based on the procedure suggested by Watson to evaluate the goodness of fit of calibrated models. ${ }^{1}$ Watson proposed to evaluate the fit of a calibrated model by asking "How much random error would have to be added to the data generated by the model so that the autocovariances implied by the model + error match the autocovariances of the observed data?" (Watson 1993, p.1012). I use his criterion to estimate the parameters of the model: specifically, I derive the theoretical evolution of the aggregate price level implied by the model specification, and then I search over the range of admissible parameters (those that satisfy the theoretical restrictions of the model), for those values that minimize the distance between the model and the data. I also seek to characterize in various ways the nature of the discrepancy between the predicted and actual price series.

Specifically, I take as given the paths of nominal labor compensation, labor productivity, and output, and then determine the path of prices predicted by the sticky price model examined. Because prices are not a stationary series, I present my results in terms of the predicted path of the price/unit labor cost ratio. This path depends on a number of

\footnotetext{
${ }^{1}$ A similar approach is proposed by Diebold, Ohanian and Berkowitz (1995).
} 
parameters, and therefore I study for which values of the parameters the model best fits the data, in terms of matching both the level of the series, and its serial correlation properties. I also study the implications of each model for the path of inflation. ${ }^{2}$

The paper is organized as follows. In section 2, I present the implications of a competitive model of pricing behavior of the kind assumed in standard real business cycle models, which I will refer to as the 'benchmark' model. Motivated by the observation that the evolution of prices relative to unit labor costs is quite different from what is predicted by such a model, in section 3 I present two models with nominal rigidities, and discuss their theoretical predictions for the paths of prices and inflation. Section 4 discusses the empirical fit of the models, and section 5 concludes.

To summarize my results, I find that models of imperfect competition with nominal price rigidity deliver an extremely close approximation both to the evolution of the price/unit labor cost ratio and to the dynamics of the inflation process, even using a very simple (though familiar) measure of marginal costs, which assumes that they are proportional to unit labor costs. Among the implications of this finding are not merely evidence for a significant degree of price stickiness in the U.S., but also important support for a forwardlooking model of price setting. Finally, the degree of fit of the simple model suggests that neither variations in marginal costs unrelated to changes in unit labor costs, nor fluctuations in markups for reasons unrelated to price stickiness, are needed to explain the greater part of U.S. fluctuations in the aggregate price level.

\section{A Competitive Pricing (Benchmark) Model}

Consider a representative firm which produces a single good Y according to an aggregate Cobb-Douglas technology:

$$
Y_{t}=K_{t}^{a}\left(Z_{t} H_{t}\right)^{1-a}
$$

where $K_{t}$ and $H_{t}$ are respectively capital and labor inputs, the stochastic process $Z_{t}$ represents an aggregate labor-augmenting technological progress, and $0<a<1$.

Assuming that both output and input markets are perfectly competitive, profit maximization implies that, in equilibrium, real wages are equal to the marginal product of labor, or that

$$
P_{t}=W_{t} / M P L_{t}
$$

The assumption of a Cobb-Douglas technology implies that the marginal productivity of labor, $M P L$, is proportional to the average productivity of labor, $A P L: M P L=(1-a) Y / H$, and therefore:

$$
\ln P_{t}=\nu+\left[\ln \left(W_{t}\right)-\ln \left(A P L_{t}\right)\right]
$$

\footnotetext{
${ }^{2}$ Since the actual series for the unit labor costs is taken as given, a model that fits the price/unit labor cost series necessarily fits the inflation series as well. However, looking at the predictions for inflation suggests an additional set of statistics to use as measures of goodness of fit.
} 
where $\nu \equiv \ln (1 /(1-a))$; in words, this model of pricing behavior implies that the ratio of prices to unit labor cost (where unit labor cost, $U L C$, is the ratio of wages to labor productivity) is constant. ${ }^{3}$

Defining $\pi_{t}=P_{t} / P_{t-1}$, and, for any other variable $x, \gamma_{x t}=x_{t} / x_{t-1}$, and denoting by $\widehat{x}_{t}$ the $\log$ deviation of variable $x$ from its steady state value $x^{*}\left(\widehat{x}_{t}=\ln \left(x_{t} / x^{*}\right)\right)$, from expression (2.3) one immediately obtains a second implication of the model: inflation is equal to the rate of change of unit labor costs:

$$
\widehat{\pi}_{t}=\widehat{\gamma}_{u l c, t}
$$

To verify the implications of this benchmark model, I consider the historical series of the price/unit labor cost ratio and inflation. The price series $(P)$ is the implicit deflator of private $G D P,{ }^{4} \mathrm{~W}$ is compensation per hour in the nonfarm private business sector; average labor productivity $(A P L)$ is productivity per hour in the same sector. All data are quarterly, from 1959:3 to 1997:1. Figure 1 plots the historical behavior of these series together with the implied series of unit labor costs; ${ }^{5}$ figure 2 plots the two series that I shall primarily seek to explain: the price/unit labor cost ratio and the inflation rate. ${ }^{6}$

Figure 2 also plots the predictions of the benchmark model for these last two series, given the evolution of unit labor costs shown in Fig.1. While the model implies that the ratio of prices to unit labor costs is a constant, equal to the inverse of the output elasticity with respect to labor, the graph in the top panel of the figure shows that this implication is clearly counterfactual. The bottom panel, which compares actual inflation (solid line) with model inflation (dotted line), reveals also that the benchmark model overstates the variability of inflation quite significantly.

I now explore the extent to which allowing for nominal price rigidity can improve upon these predictions. Of course, the neglect of nominal price rigidity need not be the only way in which the benchmark model is mis-specified: Even within the context of a competitive model with flexible prices, one might consider various reasons why marginal costs may not move in exact proportion to unit labor costs. These include a non Cobb-Douglas production function, the presence of overhead labor, the existence of adjustment costs for labor and/or variable labor utilization, and variations in other input margins, such as the capital stock, or intermediate inputs. The consequences of such factors for the proper measurement of marginal cost are taken up in Bils (1987) and Rotemberg-Woodford (1998), and the contribution of such factors to the explanation of variations in the price/unit labor cost ratio (or, alternatively, the labor share) is considered in Blanchard (1997) and Sbordone (1998).

\footnotetext{
${ }^{3}$ To say it in an alternative way, there is no markup of prices over marginal cost (in this model $\mu_{t}$, defined as the ratio $P_{t} / M C_{t}$, is just $(1-a) P_{t} / U L C_{t}$, and it is equal to 1$)$.

${ }^{4}$ Private $G D P$ is obtained by subtracting from total gross domestic product the value added of government (obtained from table 1.8 of NIPA); this is slightly different from value added of the private business sector, because it also includes two other small components, the value added of 'households and institutions', and 'farm businesses'.

${ }^{5}$ All the graphs plot the logarithm of the series.

${ }^{6}$ These series are plotted in deviation from the mean.
} 
Alternatively, one might consider imperfectly competitive flexible-price models where the price-cost margin is not constant because it is optimal for firms to vary it. Well-known examples include the 'customer market' model of Phelps and Winter (1970), and the implicit collusion model of Rotemberg and Woodford (1992), which both imply that markups should vary as a function of the ratio of expected future profits to current sales. Preliminary study (Sbordone, 1998) indicates, however, that none of these factors alone can account for a very large fraction of the observed variability of the price/unit labor cost ratio in the U.S. data, though they can account for some of it. Instead, I find that a very simple model of sticky prices, that abstracts from all of the complications just listed, does quite well. Hence I pursue that line of investigation here, leaving for future work a consideration of the extent to which such additional factors may allow an even closer fit to the data.

In the following section, I explore the implications of two standard models of nominal price rigidity. They differ from the benchmark model in that firms supply their output in imperfectly competitive markets, and prices are not completely flexible. In the first, based on Rotemberg (1982), this rigidity is due to firms facing, at any point in time, some convex cost of adjusting their price. In the second, based on Calvo (1983), price rigidity is determined by a random draw of the firms that, at any point in time, are allowed to adjust their price. The objective is to derive the implications of the two models for the path of aggregate prices and inflation, compare these predictions to the data, and discuss the interpretation of the empirical results in terms of the key parameters measuring the degree of price stickiness in the two models, respectively the cost of adjusting prices, and the average time between price changes.

\section{Models with Nominal Price Rigidity}

\subsection{A Model with Costs of Adjusting Prices}

In this model I introduce monopolistic competition among firms, while maintaining the standard Cobb-Douglas technology for each firm, so that marginal cost can still be measured by unit labor cost. The possibility of markup fluctuations is created by introducing nominal rigidities, arising from some costs of adjusting prices that firms face every period (as in Rotemberg 1982, 1995).

The model has a continuum of monopolistic firms, indexed by $i$, which produce differentiated goods, also indexed by $i$. The demand curve for product $i$ takes the form:

$$
Y_{i t}=\left(P_{i t} / P_{t}\right)^{-\theta} Y_{t}
$$

where $\theta$ is the Dixit-Stiglitz elasticity of substitution among differentiated goods, and $Y_{t}$ is the aggregator function defined as $Y_{t}=\left[\int_{0}^{1} Y_{i t}^{(\theta-1) / \theta} d i\right]^{\theta /(\theta-1)}$.

Each firm $i$ has a Cobb-Douglas production technology:

$$
Y_{i t}=\left(K_{i t}\right)^{a}\left(Z_{t} H_{i t}\right)^{1-a}
$$


and faces convex costs of adjusting its own price $P_{i t}$, where these costs increase proportionally with the size of the economy:

$$
\phi\left(\ln \left(P_{i t} / P_{i t-1}\right)\right) P_{t} Y_{t}
$$

$P_{t}=\left[\int_{0}^{1} P_{i t}^{1-\theta} d i\right]^{1 /(1-\theta)}$ is the aggregate price level. I assume that the convex function $\phi()$ takes its minimum value of zero when evaluated at the steady state value of $\ln \left(P_{i t} / P_{i t-1}\right)$, which I also take to be zero: thus $\phi(0)=\phi^{\prime}(0)=0$ and $\phi^{\prime \prime}>0$.

The objective of firm's $i$ (supplier of good $i$ ) is to maximize the expected sum of future discounted profits:

$$
E_{t}\left\{\sum_{j=0}^{\infty} R_{t, t+j} \Pi_{i t+j}\right\}
$$

subject to the technology and the demand constraints. $R_{t, t+j}$ is a stochastic discount factor, and period $t$ profits are given by: $\Pi_{i t}=P_{i t} Y_{i t}-W_{t} H_{i t}-\rho_{t} K_{i t}-\phi\left(\ln P_{i t} / P_{i t-1}\right) P_{t} Y_{t}$.

The first order condition for the optimal choice of $P_{i t}$, evaluated at a symmetric equilibrium, where $P_{i t}=P_{t}, H_{i t}=H_{t}, Y_{i t}=Y_{t}$, for each period $t$ and for all $i,{ }^{7}$ implies that

$$
P_{t}=\mu_{t} S_{t}
$$

where $S_{t}=\frac{1}{1-a} \frac{W_{t}}{A P L_{t}}$, and where the variable $\mu_{t}$ is defined as

$$
\mu_{t}=\theta\left[(\theta-1)+\phi^{\prime}\left(\ln \pi_{t}\right)-E_{t} R_{t, t+1} \pi_{t+1} \gamma_{y t+1} \phi^{\prime}\left(\ln \pi_{t+1}\right)\right]^{-1}
$$

Alternatively:

$$
\frac{P_{t}}{U L C_{t}}=\frac{\mu_{t}}{1-a}
$$

which, taking logarithms of both sides is

$$
\ln \mu_{t}=\ln (1-a)+\ln P_{t}-\ln U L C_{t}
$$

Unlike in the benchmark model case, the price/unit labor cost ratio in this model is not predicted to be a constant, but varies with $\mu_{t}$. To evaluate its theoretical behavior, I therefore take a log-linear approximation of $\mu_{t}$ around its steady state value $\mu^{*}$ (where the assumptions made about the function $\phi\left(\right.$ ) imply that $\left.\mu^{*}=\frac{\theta}{\theta-1}\right)$. The approximation gives ${ }^{8}$

$$
\widehat{\mu}_{t}=-\frac{\phi^{\prime \prime}(0)}{\theta-1}\left[\widehat{\pi}_{t}-R \gamma_{y}^{*} E_{t} \widehat{\pi}_{t+1}\right]
$$

where $R$ is the steady-state value of the discount factor $R_{t, t+1}$. This equation can be written as

$$
\widehat{\mu}_{t}=-\alpha_{0}\left[\widehat{\pi}_{t}-\alpha_{1} E_{t} \widehat{\pi}_{t+1}\right]
$$

${ }^{7}$ See Appendix, section 6.1, for details of the calculations.

${ }^{8}$ See Appendix, section 6.1.2. 
where $\alpha_{0}\left(\equiv \phi^{\prime \prime}(0) /(\theta-1)\right)$ is a measure of the curvature of the adjustment cost function, and $\alpha_{1}\left(=R \gamma_{y}^{*}\right)$ reflects the steady state growth of output; conveniently rewritten, by using expression (3.5) to substitute for $\ln \mu_{t}$ (where $\ln \mu_{t}=\widehat{\mu}_{t}+\ln \mu^{*}$ ) it describes the dynamic of inflation in terms of future expected inflation and average real marginal costs:

$$
\widehat{\pi}_{t}=\alpha_{1} E_{t} \widehat{\pi}_{t+1}+\frac{1}{\alpha_{0}}\left(u l c_{t}-p_{t}-\kappa\right)
$$

where lowercase letters denote natural logs of the corresponding upper case letters, and $\kappa=\ln ((1-a)(\theta-1) / \theta)$. The implied path of aggregate prices is easily derived: write the above equation as an expression for unit labor costs:

$$
u l c_{t}-p_{t}=\kappa+\alpha_{0}\left[\Delta p_{t}-\alpha_{1} E_{t} \Delta p_{t+1}\right]
$$

Solving this expression for the optimal price path, one gets prices as a weighted average of past prices and expected future unit labor $\operatorname{costs}^{9}$

$$
p_{t}=\lambda_{1} p_{t-1}+\left(1-\lambda_{1}\right)\left[\left(1-\lambda_{2}^{-1}\right) \sum_{j=0}^{\infty} \lambda_{2}^{-j} E_{t}\left(u l c_{t+j}-\kappa\right)\right]
$$

where $\lambda_{1}$ and $\lambda_{2}$ are the real roots of the characteristic polynomial of the difference equation in $p_{t}, P(\lambda)=\alpha_{1} \lambda^{2}-\left(1+\alpha_{1}+\alpha_{0}^{-1}\right) \lambda+1=0$, with $0<\lambda_{1}<1<\lambda_{2}$.

Denoting by $F_{t}$ the forward-looking component term which is in square brackets $\left(F_{t} \equiv\right.$ $\left.\left(1-\lambda_{2}^{-1}\right) \sum_{j=0}^{\infty} \lambda_{2}^{-j} E_{t}\left(u l c_{t+j}-\kappa\right)\right)$, eq. (3.9), can be conveniently rewritten as

$$
p_{t}=\left(1-\lambda_{1}\right) \sum_{j=0}^{\infty} \lambda_{1}^{j} F_{t-j}
$$

This equation forms the basis for the computation of the theoretical path of prices.

The evolution of inflation described by eq.(3.8) is typically used to construct an 'expectation augmented', or 'New Keynesian', Phillips Curve (the equation most often estimated in empirical studies). Using additional assumptions about preferences that allow one to derive a labor supply function, the real marginal costs can be written as function of the deviation of aggregate activity from some potential level:

$$
(M \widehat{C / P})_{t}=\eta\left(\widehat{Y}_{t}-\widehat{Y}_{t}^{p}\right)
$$

with $\eta>0$. Since unit labor cost is proportional to the real marginal cost, $M C / P$, it follows that $(U \widehat{L C} / P)_{t}=(M \widehat{C / P})_{t}$. Therefore, substituting (3.11) in eq. (3.8) one gets an expectations augmented Phillips Curve:

$$
\widehat{\pi}_{t}=\gamma\left(\widehat{Y}_{t}-\widehat{Y}_{t}^{p}\right)+\alpha_{1} E_{t} \widehat{\pi}_{t+1}
$$

where $\gamma \equiv \frac{\eta}{\alpha_{0}}$, which is the formulation estimated, for example, in Roberts (1995).

${ }^{9}$ See Appendix, section 6.1.3. 


\subsection{A Model with Random Intervals Between Price Changes}

Before turning to the empirical evaluation of the model, I want to show how it is possible to derive eq. (3.8) from a different hypothesis about nominal rigidities, like that formulated by Calvo (1983). The fact that this alternative model yields a supply curve as that implied by the Rotemberg model was first shown by Rotemberg (1987). ${ }^{10}$ However, it is worth reviewing the nature of this observational equivalence, for the light that it sheds on the price stickiness parameter $\alpha_{0}$.

Since Rotemberg does not derive an equation corresponding to (3.8) for either model, he does not discuss the interpretation of the parameter that is estimated here. Many recent derivations of the aggregate supply relation implied by a discrete-time version of the Calvo model, like that of Woodford (1996), similarly omit any explicit tretment of the factor markets, and so obtain no equation relating prices to labor costs. Finally, even those derivations that do include the labor market, such as those of Yun (1996), King and Watson (1996), or Goodfriend and King (1997), make a different assumption than mine about factor mobility among firms, that has an important effect upon the interpretation of $\alpha_{0}$. Hence it is useful to review the implications of this model, emphasizing its consequences for the relation between prices and unit labor costs.

As in the previous model, there is a continuum of firms, each operating with a CobbDouglas technology (3.2), and facing a demand curve as (3.1); in addition, in every period, a fraction $(1-\alpha)$ of the firms can set a new price, independently of the past history of price changes, which will then be kept fixed until the next time the firm is drawn to change prices again. This set-up implies that the expected time between price changes is $\frac{1}{(1-\alpha)}$. By letting $\alpha$ vary between 0 and 1, the model nests a wide range of assumptions about the degree of price stickiness, from perfect flexibility $(\alpha=0)$ to complete price rigidity (the limit as $\alpha \rightarrow 1)$.

The pricing problem of a firm that revises its price in period $t$ is again to choose its price, which I will indicate as $X_{i}$, to maximize its expected stream of profits, which is

$$
E_{t}\left\{\sum_{j=0}^{\infty} R_{t, t+j} \Pi_{i t+j}\right\}
$$

Then the first order condition for the optimal price is

$$
E_{t}\left\{\sum_{j=0}^{\infty} \alpha^{j} R_{t, t+j}\left[(1-\theta) X_{t} Y_{i t+j}+\frac{\theta}{1-a} W_{t+j} H_{i t+j}\right]\right\}=0
$$

where, because each firm that is allowed to change prices solves the same problem, I have suppressed the subscript $i$ on $X_{t}$ (although I need to maintain it for output and hours, to distinguish individual from aggregate quantities). Rewrite this expression as

$$
\sum_{j=0}^{\infty} \alpha^{j} E_{t}\left\{R_{t, t+j} Y_{i t+j}\left[X_{t}-\frac{\theta}{\theta-1}\left(\frac{1}{1-a} \frac{W_{t+j} H_{i t+j}}{Y_{i t+j}}\right)\right]\right\}=0
$$

\footnotetext{
${ }^{10}$ See also Roberts (1995).
} 
Then, denoting by $S_{t+j, t}$ the marginal cost of producing, at date $t+j$, goods whose price was set at time $t$ (so $S_{t+j, t} \equiv \frac{1}{1-a} \frac{W_{t+j} H_{i t+j}}{Y_{i t+j}}$ ), substitute the demand constraint for $Y_{i t+j}$, to get:

$$
\sum_{j=0}^{\infty} \alpha^{j} E_{t}\left\{R_{t, t+j} Y_{t+j}\left(\frac{X_{t}}{P_{t+j}}\right)^{-\theta}\left[X_{t}-\frac{\theta}{\theta-1} S_{t+j, t}\right]\right\}=0
$$

Finally, divide this expression by $P_{t}$, define $x_{t} \equiv X_{t} / P_{t}$ and $s_{t+j, t} \equiv S_{t+j, t} / P_{t+j}$, and rewrite it as

$$
\sum_{j=0}^{\infty} \alpha^{j} E_{t}\left\{R_{t, t+j} Y_{t+j}\left(\frac{X_{t}}{P_{t+j}}\right)^{-\theta}\left[x_{t}-\frac{\theta}{\theta-1} s_{t+j, t} \prod_{k=1}^{j} \pi_{t+k}\right]\right\}=0
$$

This optimal pricing condition, combined with the distribution of aggregate prices at any point in time, allows one to describe the path of aggregate prices and inflation in this model.

The distribution of aggregate prices at time $t$ is a mixture of the distribution of prices of the previous period (since all previous prices have the same probability of being changed), with weight $\alpha$, and the new price $X_{t}$, with weight $(1-\alpha)$

$$
P_{t}=\left[(1-\alpha) X_{t}^{1-\theta}+\alpha P_{t-1}^{1-\theta}\right]^{\frac{1}{1-\theta}}
$$

Dividing both sides by $P_{t}$, and defining $\pi_{t} \equiv P_{t} / P_{t-1}$, a log linear approximation of this expression is:

$$
0=(1-\alpha) \widehat{x}_{t}-\alpha \widehat{\pi}_{t}
$$

or

$$
\widehat{\pi}_{t}=\frac{1-\alpha}{\alpha} \widehat{x}_{t}
$$

Similarly, a log-linear approximation of $(3.14)$ around $x^{*}(\equiv 1), s^{*}\left(\equiv \frac{\theta-1}{\theta}\right)$, and $\pi^{*}(\equiv 1)$, gives:

$$
\widehat{x}_{t}=\left(1-\alpha R \gamma_{y}^{*}\right) \Sigma_{j=0}^{\infty}\left(\alpha R \gamma_{y}^{*}\right)^{j} E_{t}\left(\widehat{s}_{t+j, t}+\Sigma_{k=1}^{j} \widehat{\pi}_{t+k}\right)
$$

where again $R$ is the steady state value of the stochastic discount factor $R_{t, t+j}$, and $\gamma_{y}^{*}$ is the steady state growth rate of output. Combining expressions (3.16) and (3.17) one obtains a relationship between current and expected inflation of the kind obtained for the model with cost of adjusting prices.

To get such a relationship, we should write explicitly what the marginal cost is. Using the production technology to express hours in terms of output, and the demand constraint, we get

$$
s_{t+j, t} \equiv \frac{1}{1-a} \frac{W_{t+j} H_{i t+j}}{P_{t+j} Y_{i t+j}}=\left(\frac{1}{1-a} \frac{W_{t+j} H_{t+j}}{P_{t+j} Y_{t+j}}\right)\left[\left(\frac{X_{t}}{P_{t+j}}\right)^{-\theta}\right]^{\frac{a}{1-a}}
$$

under the assumption that firms' relative capital stocks do not vary with their relative prices, or relative production levels. (This means that I assume that capital is not reallocated across firms istantaneously, so as to equate the shadow price of capital services at all times, as assumed in papers such as Yun (1996) and Goodfriend and King (1997).) 
This expression shows that the real marginal cost of the firms that are allowed to charge a new price need not be the same as the average level of real marginal cost for firms in general, which is the term in brackets $\left(\frac{1}{1-a} \frac{W_{t+j} H_{t+j}}{P_{t+j} Y_{t+j}} \equiv s_{t+j}^{a v g}\right.$ ). (Our data on unit labor costs measure the average level of costs, of course, not the level specific to firm $i$ ). In this model, the extent to which, at any point in time, firms charge different relative prices, determines firms' different levels of sales, and hence their different levels of marginal costs. Specifically,

$$
s_{t+j, t}=s_{t+j}^{a v g} *\left[\left(\frac{X_{t}}{P_{t+j}}\right)^{-\theta}\right]^{\frac{a}{1-a}}
$$

A log linear approximation of this equation around the steady state values of $s_{t+j, t}$ and $x_{t}$ gives

$$
\widehat{s}_{t+j, t}=\widehat{s}_{t+j}^{a v g}-\frac{\theta a}{1-a}\left(\widehat{x}_{t}-\Sigma_{k=1}^{j} \widehat{\pi}_{t+k}\right)
$$

Substituting (3.19) into (3.17), using the relationship between $\widehat{\pi}_{t}$ and $\widehat{x}_{t}$ of eq.(3.16), and further simplifying ${ }^{11}$ one gets

$$
\begin{aligned}
\widehat{\pi}_{t} & =\left(\frac{\left(1-\alpha R \gamma_{y}^{*}\right)(1-\alpha)}{\alpha}\right)\left(\frac{1-a}{1-a+a \theta}\right) \widehat{s}_{t}^{a v g}+R \gamma_{y}^{*} E_{t} \widehat{\pi}_{t+1} \\
& \equiv \frac{1}{\alpha_{0}} \widehat{s}_{t}^{a v g}+\alpha_{1} E_{t} \widehat{\pi}_{t+1}
\end{aligned}
$$

where now $\alpha_{0} \equiv\left(\frac{\alpha}{\left(1-\alpha R \gamma_{y}^{*}\right)(1-\alpha)}\right)\left(\frac{1-a+a \theta}{1-a}\right)$ and again $\alpha_{1} \equiv R \gamma_{y}^{*}$.

Like eq.(3.8) of the previous model, where firms face costs of adjusting prices, the pricing behavior of the firms in this model leads to a similar implication about inflation dynamics: Inflation depends on expected future inflation and real marginal costs. This correspondence allows one to interpret the estimate of the cost of adjusting prices (the parameter $\alpha_{0}$ ) of the first model with nominal rigidities examined, in terms of the average expected time between price changes (the parameter $1 /(1-\alpha)$ ), that characterizes this model.

It should be noted that the assumption that we need to make about capital mobility in this model affects only the quantitative interpretation of this correspondence. In the case in which the marginal cost of the firms that set new prices is not different from the average marginal cost, because capital is istantaneously reallocated across firms to equalize the shadow price of capital services, $\widehat{s}_{t+j, t}=\widehat{s}_{t+j}^{a v g}$, and the parameter $\alpha_{0}$ in expression (3.20) simplifies to

$$
\alpha_{0}=\frac{\alpha}{\left(1-\alpha R \gamma_{y}^{*}\right)(1-\alpha)}
$$

but the nature of the relationship that describes inflation dynamics remains unaltered.

\footnotetext{
${ }^{11}$ See section 6.2 of the Appendix.
} 


\section{Empirical Results}

\subsection{The Fit of the Model}

I now proceed to evaluate the empirical predictions of the model with cost of adjusting prices: using time series of unit labor costs, and a forecasting model to compute expectations of future unit labor cost, I derive the predicted path of the price level according to eq.(3.10), and discuss the parameter choice that best fits the model to the data.

To compute the expected future unit labor costs, I assume that all information at time $t$ about current and future values of the unit labor cost can be summarized by a vector of variables $Z_{t}$, which include the unit labor cost, and also that $\left\{Z_{t}\right\}$ is a stationary Markov process: $Z_{t+1}=\Gamma Z_{t}+\varepsilon_{Z t+1}$. Given a forecast for the unit labor costs, and parameter values for $\lambda_{1}$ and $\lambda_{2}$, one can compute the path of prices implied by (3.10), and therefore the path of the two series of interest, namely the price/unit labor cost ratio, and the inflation process. The model is then evaluated by measuring its ability to match the actual behavior of these two series and their serial correlation properties.

The distance between the model and the data measures the error that one commits when approximating the data with the model prediction. I choose the variance of this distance as a criterion function to evaluate the goodness of fit of the model, namely I select for the model parameters the values that minimize this function.

Let $\epsilon_{t}^{p}$ be defined as:

$$
\epsilon_{t}^{p}=\left[p_{t}-u l c_{t}\right]^{\text {mod el }}-\left[p_{t}-u l c_{t}\right]^{\text {data }}=p_{t}^{\text {mod el }}-p_{t}^{\text {data }}
$$

and $\left[p_{t}-u l c_{t}\right]^{\bmod \mathrm{el}}=f(\underline{\Psi})$, where $\underline{\Psi}$ is the vector of unknown parameters: I estimate the parameters value by:

$$
\widehat{\Psi}=\arg \min \operatorname{var}\left(\epsilon_{t}^{p}\right) .
$$

To estimate a forecasting system for $Z$, I fit a 3 -variable $V A R$ to time series of unit labor cost, output, and the price/ cost ratio. Based on the stationarity properties of the time series under investigation, unit labor costs, prices, and output are all assumed to be $I(1)$ processes, while the price/unit labor cost ratio is assumed stationary. ${ }^{12}$ The $V A R$ vector therefore includes the rate of change of the unit labor cost (which corresponds to $\widehat{\gamma}_{u l c, t}$ in the model), the rate of change of private $G D P$, and the ratio of prices to unit labor costs. Two lags of the dependent variables are included. Denoting by $X_{t}$ the vector of dependent variables $X_{t}=\left[\begin{array}{lll}\Delta u l c_{t} \Delta y_{t} & p_{t}-u l c_{t}\end{array}\right]^{\prime}$, the vector $Z_{t}$ is defined as $Z_{t}=\left[\begin{array}{ll}X_{t} & X_{t-1}\end{array}\right]^{\prime}$.

The statistical properties of the optimal price process, and therefore of the price/cost ratio and inflation, in the model, depend upon the parameters $\lambda_{1}$ and $\lambda_{2}$, which are the roots of the polynomial $P(\lambda)=0$, and therefore depend upon the parameters $\alpha_{0}$ and $\alpha_{1}$. Of these parameters, the most important is $\alpha_{0}$, which measures the curvature of the cost of price adjustment. The parameter $\alpha_{1}$, which is equal to $\gamma_{y}^{*} R$, should be very close to 1 , if

\footnotetext{
${ }^{12}$ These assumption are based on the results of standard Dickey-Fuller and Stock-Watson tests for the presence of unit roots and cointegration.
} 
one approximates the steady state value of output growth with the average over the sample period considered, ${ }^{13}$ and assumes, quite reasonably, a discount factor $R$ almost equal to 1 . In the results presented here, I therefore set $\alpha_{1}=1 .{ }^{14}$ To estimate $\alpha_{0}$, for the given value of $\alpha_{1}$, I search over the space of positive values of $\alpha_{0}$ to find the value that minimizes the variance of the distance between the ratio of prices to unit labor costs implied by the model, and the corresponding ratio computed in the data. ${ }^{15}$ This value (see figure 3 ) is $17.5{ }^{16}$ The figure shows clearly, however, that even values of $\alpha_{0}$ much smaller than that improve significantly upon the fit of the flexible price model $\left(\alpha_{0}=0\right)$ : for example, for $\alpha_{0}=2$, the distance between model and data is reduces by more than $40 \%$.

I then set $\alpha_{0}$ equal to the estimated value of 17.5 , and construct a theoretical prices to unit labor cost ratio: the variance of the distance of this series from the price/unit labor cost ratio computed in the data is $88 \%$ lower than that of the benchmark model. Figure 4 shows how close is the theoretical series to the data, for this particular parametrization. ${ }^{17}$ Moreover, the model can account extremely well for the entire autocorrelation function of the price/ulc ratio (fig. 5).

Finally, the fit of the model relative to inflation is shown in figure 6 , which plots the inflation series constructed according to this model against actual inflation. For comparison, one should look at the bottom panel of figure $2 \mathrm{~b}$, where the same inflation data are plotted against the inflation series predicted by the benchmark model. It is clear that in this model inflation volatility is notably reduced, compared to the benchmark model (it declines by $66 \%$ ), and the distance between the model inflation and data is reduced by $96 \%$, compared to the benchmark model.

The autocorrelation function of inflation is also very closely matched (see fig. 7).

\subsection{A Further Test of the Model Restrictions: Do the Forward-looking Terms Matter?}

A crucial feature of this model is the importance assigned to the forward-looking component of the price setting behavior. This feature represents an important departure from the older literature on price/cost margins. A typical price equation from the 1960's (see, e.g., Eckstein and Fromm, 1968) posits prices as a function of unit labor costs, but includes only the current and lagged values of these costs as explanatory variables. Other variables typically enter the regression to account for other cost or demand factors. Here expectations of future unit

\footnotetext{
${ }^{13}$ This approximation gives $\gamma_{y}^{*}=1.0084$.

${ }^{14}$ I consider later the consequences of treating $\alpha_{1}$ as a free parameter as well.

${ }^{15}$ Because I forecast the rate of change of unit labor costs, I use a transformation of eq.(3.10) that directly computes the theoretical price/unit labor cost ratio. See appendix, section 6.1.3.

${ }^{16}$ The standard error for this parameter, computed via a non linear least squares routine, is 2.09 .

${ }^{17}$ Note that I am working in deviations from the mean. The deviation of $\mathrm{p} / \mathrm{ulc}$ is therefore not affected by the parameters $a$ and $\theta$, respectively the elasticity of output with respect to capital and the Dixit-Stigliz elasticity of substitution among differentiated goods.
} 
labor costs also enter, with quite a large weight. And interestingly, the other variables, such as material prices, ratio of unfilled orders to sales, operating rate, are not needed in order to account for a very large fraction of the overall variation in the price level in the data. A possible interpretation, consistent with the theoretical framework proposed here, is that the other variables entered significantly in traditional price equations because they were proxies for the omitted expectations terms. In that case, treating these estimated equations as structural for purposes of policy analysis would be vulnerable to the Lucas (1976) critique.

But some recent studies have questioned the importance of the forward looking component in pricing behavior, by focusing on the empirical validity of the inflation equation that it implies. Typically, an inflation equation of the kind analyzed in this paper is estimated in the form of the 'New Keynesian' Phillips curve (as eq.(3.12)) which combines the inflation equation derived from a model with price rigidities (eq.(3.8) or (3.20)) with a relationship between real marginal cost and output, and the empirical results are often discussed as a 'test' of the importance of nominal rigidities, or of the role of forward looking behavior in the price setting mechanism. For example, Fuhrer's (1997) empirical results point to a negligible role of future inflation in an estimated inflation-output relationship, specified in a way that is intended to nest the 'New Keynesian' Phillips Curve specification, the more complex variant proposed by Fuhrer and Moore (1995), and purely backward-looking Phillips Curve specifications. Roberts $(1997,1998)$ instead argues that the 'New Keynesian' Phillips Curve fits reasonably well when survey measures of inflation expectations are used to estimate it, but that it does not fit well under the hypothesis of rational expectations. He thus proposes a model with an important backward-looking component in the inflation expectations, which amounts to weakening the weight put on the forward-looking terms in his aggregate supply relation.

Here I propose instead to address the question of whether the forward-looking term in my pricing equation matter, abstracting from any assumption about how marginal costs are related to the level of economic activity. ${ }^{18}$

From the definition of $F_{t}$ in eq. (3.10), one sees that the expected evolution of unit labor costs in the future matters only insofar as the parameter $\lambda_{2}^{-1} \neq 0$. Moreover, the model implies that the parameters $\lambda_{1}$ and $\lambda_{2}$ are constrained to be in a specific relationship with the structural parameters $\alpha_{0}$ and $\alpha_{1}$. To test these implications, I reestimated the price equation without imposing the constraints on $\lambda_{1}$ and $\lambda_{2}$. The results reported below indicate that both parameters are statistically significant; moreover, although a formal test rejects the hypothesis that the product of $\lambda_{1}$ and $\lambda_{2}$ is equal to 1, as the assumption I made of $\alpha_{1}=1$ in the model implies, ${ }^{19}$ the surface plot in fig. 8 shows that no significant reduction

\footnotetext{
${ }^{18}$ The approach of Gali and Gertler (1998) is in the same spirit. Although they use a methodology different from mine, they stress the same point, that the relation predicted by the theory, and to be investigated empirically, is the one linking inflation to the stream of future real marginal costs.

${ }^{19}$ The optimal value of $\alpha_{1}$ is in fact 1.07 (s.e.=.006), which is significantly different from 1 , and the corresponding optimal value of $\alpha_{0}$ is 36.5. Although this pair of values improves further the fit of the model (the variance of the distance between the theoretical and the actual price/unit labor cost ratio is now reduced by $95 \%$ ), it is hard to interpret a value of of $\alpha_{1}>1$, because it would imply a discount factor $R$ also bigger
} 
of the distance between model and data could be achieved if $\lambda_{2}^{-1}$ is not close to the value of $\lambda_{1}$.

\begin{tabular}{|cc|}
\hline Unconstrained parameter estimates & \\
\hline Un & \\
\hline$\hat{\lambda}_{2}^{-1}=$ & .879 \\
$\widehat{\lambda}_{1}=$ & $\begin{array}{l}.006) \\
\end{array}$ \\
& $(.005)$ \\
& \\
\hline
\end{tabular}

These results suggest that the forward looking component in the price equation is quite important. They also suggest that the inflation dynamics implied by this forward-looking model, according to which inflation is a function of expected future inflation and real marginal costs, does indeed describe very closely the dynamics of the data. As a consequence, it may not be necessary to hypothesize forms of departure from full rationality (as Roberts 1997, 1998 does), or to introduce additional inertia in the inflation process (as in Fuhrer 1997). If there is a mis-specification in the inflation-output relationship described by the "New Keynesian' Phillips Curve, this may not be due to the theoretical link between inflation and real marginal costs, but to the additional assumptions about the relationship between marginal costs and output.

\subsection{Interpretation of the Degree of Stickiness}

In the empirical literature, convex costs of adjusting prices are often further specified to be quadratic, for the purpose of econometric estimation. Among the most recent studies, Roberts, Stockton and Struckmeyer (1994) estimate an econometric model of imperfectly competitive firms with U.S. industry data, and find relatively small values for the adjustment cost parameter: 0.57 for the manufacturing sector, and values ranging from insignificantly different from zero to significant 2.8 for the individual two-digit sectors. In another study, Ireland (1996) estimates a small, structural, general equilibrium model for the U.S. economy, in which firms face quadratic costs of adjusting prices, and obtains an estimate of 4.05 for the coefficient of the quadratic cost function. A direct comparison with these studies is, however, difficult. Unlike the first paper, the estimates obtained here use quarterly, aggregate data, and a different econometric approach; unlike the second paper, the results do not depend upon a number of assumptions that go beyond the specific price mechanism. In interpreting the size of the parameter $\alpha_{0}$, anyway, it is worth stressing again that, although the optimal value is estimated to be 17.5, the goodness of fit of the price/ unit labor cost in this model

than 1.

${ }^{20}$ In parentheses are reported standard errors, obtained by a non-linear least squares routine. Bootstrap standard errors are virtually the same. 
is significant, even for much lower values of this parameter; as fig. 3 shows, the largest gain over the benchmark flexprice model occurs when $\alpha_{0}$ moves from 0 to around 4 .

A useful way to interpret the degree of stickiness implied by costs of adjusting prices of the size estimated, is in terms of its implications for the length of the expected time between price changes implied by the Calvo model of section 3.2. Consider equation (3.20): in the case in which all firms face the same real marginal cost, $\alpha_{0}=\frac{\alpha}{(1-\alpha)\left(1-\alpha R \gamma_{y}^{*}\right)}=\frac{\alpha}{(1-\alpha)^{2}}$, where the second inequality follows from the imposed value of 1 for $\alpha_{1}\left(\equiv R \gamma_{y}^{*}\right)$. In this case, (which implies a discount rate $R=.996$ ), the estimated value of the cost of adjusting prices $\left(\alpha_{0}=17.5\right)$ is consistent with an average expected time between price changes of about 14 months. As argued before, however, a more realistic case is one in which there is a wedge between the firm's and the average real marginal cost, in which case the stickiness parameter is $\alpha_{0}=\frac{\alpha}{(1-\alpha)\left(1-\alpha R \gamma_{y}^{*}\right)}\left(\frac{1-a+a \theta}{1-a}\right)$ : it may therefore be important which values one wants to assume for the share of capital $a$ and the Dixit-Stiglitz elasticity of substitution among differentiated goods $\theta$. For example, still for the case of an implied discount rate $R=.996, \alpha_{0}=17.5$ is consistent with $a=.25, \theta=6$ (which implies an average value of markup of 1.2), and $1 / 3$ of the firms changing prices at any point in time $(\alpha=.66)$; in this case the average time between price changes is only 9 months. Increasing the average value of markup (i.e. lowering $\theta$ ), for any given value of the capital share $a$, increases modestly the estimated value of $\alpha$ : for example, an average markup of 1.6, for $a=.25$, brings the fraction $\alpha$ to .72, and the estimated average time between price changes to slightly less than 11 months. Viceversa, for any given value of $\theta$, increasing the assumed capital share reduces the fraction $\alpha$ : for example, for $\theta=6$, increasing the capital share to $1 / 3$, makes the estimated value of the cost of adjusting prices consistent with $63 \%$ of the firms keeping prices constant from one period to the other, which implies an average expected time between price changes again of little above 8 months.

Summing up, varying the parameters calibration within the range discussed suggests an estimated range of price inertia between $2 \frac{1}{2}$ and $3 \frac{1}{2}$ quarters. These numbers are in line with more direct empirical estimates of the frequency of price adjustment: for example, in a survey of about 200 manufacturing firms, Blinder et al. (1998) report that $65 \%$ of the firms claim between one and two price changes over the year; also, the median time between price changes appears to be 9 months. ${ }^{21}$

The following table summarizes the 'goodness of fit' of the model, measured by the reduction of the distance between model and data, for several values of the cost of adjusting prices, interpreted in terms of the average time between price adjustments, using benchmark values for $a$ and $\theta$. The third column reports, for each value of the parameter $\alpha_{0}$, the variance of the 'error' of the model, and the next two columns report the reduction, with respect to the variance of the benchmark model, in the distance between theoretical and actual paths of prices and inflation.

\footnotetext{
${ }^{21}$ Blinder et al. (1998), table 4.1, p. 84.
} 


\begin{tabular}{|c|c|c|c|c|}
\hline \multicolumn{5}{|c|}{ TABLE 1} \\
\hline \multicolumn{5}{|c|}{$\begin{array}{c}\text { Measures of fit as function of } \\
\text { expected time between price changes } \\
\text { (implied } \mathrm{R}=.996 \text {, basic forecasting VAR) }\end{array}$} \\
\hline$\alpha_{0}$ & $\begin{array}{l}\text { expected time } \\
(a=.25, \theta=6)\end{array}$ & $\begin{array}{l}\mathrm{V}\left(\epsilon_{t}^{p / u l c}\right) \\
\left(* \mathrm{e}^{-4}\right)\end{array}$ & $\begin{array}{l}\% \text { red. } \mathrm{V}\left(\epsilon_{t}^{p / u l c}\right) \\
\text { vs. benchmark }\end{array}$ & $\begin{array}{c}\% \text { red. } \mathrm{V}\left(\epsilon_{t}^{\pi}\right) \\
\text { vs. benchmark }\end{array}$ \\
\hline 2 & $4 \frac{1}{2}$ months & 1.457 & 43.4 & 73.8 \\
\hline 6 & 6 months & 0.750 & 70.8 & 89.9 \\
\hline 12 & $7 \frac{1}{2}$ months & 0.382 & 85.1 & 94.9 \\
\hline $\begin{array}{c}17.5 \\
\text { (s.e. } 2.09)\end{array}$ & 9 months & 0.306 & 88.1 & 96.0 \\
\hline
\end{tabular}

The table shows that even for a size of the adjustment cost corresponding to much lower price inertia (for example $\alpha_{0}=2$, which corresponds to an average expected time between price changes of less than two quarters), the goodness of fit of this model is about $40 \%$ higher than that of the benchmark model.

\subsection{Robustness to the Specification of the Forecasting System}

Finally, as one would expect, the results are somewhat sensitive to the specification of the forecasting system for unit labor costs. As an example, I report in table 2 the results obtained with a VAR which includes unit labor costs, output growth, consumption/output ratio, and hours growth. This alternative VAR is of interest as it does not use data on the price level to forecast unit labor costs, and so the predicted price level and inflation series are constructed with no reference at all to the actual price level data.

As the table shows, this specification leads to a price equation that still fits qualitatively very well, although it improves upon the benchmark model fit to a lower degree (it reduces the theoretical error in the price/cost ratio by about $60 \%$, and in inflation by little above $80 \%$ ). Interestingly, however, the best fit is obtained with a lower value of the cost of the price stickiness parameter $\alpha_{0}$. Of course, if the theoretical model is correct, one would expect that the price/unit labor cost ratio should be a good variable in the forecasting regression for future changes in the unit labor cost, so it is not surprising that the basic specification of the VAR yields better results. 


\begin{tabular}{|c|c|c|c|c|}
\hline \multicolumn{5}{|c|}{ TABLE 2} \\
\hline \multicolumn{5}{|c|}{$\begin{array}{c}\text { Measures of fit as function of } \\
\text { expected time between price changes } \\
\text { (implied } \mathrm{R}=.996 \text {, alternative forecasting VAR) }\end{array}$} \\
\hline$\alpha_{0}$ & $\begin{array}{l}\text { expected time } \\
(a=.25, \theta=6)\end{array}$ & $\begin{array}{l}\mathrm{V}\left(\epsilon_{t}^{p / u l c}\right) \\
\left(* \mathrm{e}^{-4}\right)\end{array}$ & $\begin{array}{l}\% \text { red. } \mathrm{V}\left(\epsilon_{t}^{p / u l c}\right) \\
\text { vs. benchmark }\end{array}$ & $\begin{array}{c}\% \text { red. } \mathrm{V}\left(\epsilon_{t}^{\pi}\right) \\
\text { vs. benchmark }\end{array}$ \\
\hline 2 & $4 \frac{1}{2}$ months & 1.631 & 36.6 & 65.7 \\
\hline 6 & 6 months & 1.128 & 56.2 & 80.0 \\
\hline $\begin{array}{c}9 \\
\text { (s.e. } 1.48)\end{array}$ & 7 months & 1.054 & 59.0 & 83.2 \\
\hline
\end{tabular}

\section{Conclusion}

This paper derives the implications of two models with nominal rigidities about the path of aggregate prices and inflation dynamics; it shows that such simple models deliver a very close approximation to both the price/ unit labor cost ratio and the inflation process. In particular, by introducing some degree of price stickiness, either in the form of small costs for all the firms to adjust prices, or by introducing a random draw of a fraction of the firms that are allowed to change their prices, the model predicts that aggregate prices are driven by the anticipated behavior of unit labor cost, and this predicted behavior describes very closely the actual behavior of prices.

This result is potentially interesting for two brands of the literature. On one hand, it shows that nominal rigidities are a reasonable component of general equilibrium models, like those used to describe the economy response to various kind of shocks. The failure of existing models which incorporate nominal rigidities to reproduce accurately empirical facts (see King-Watson 1996, Christiano, Eichenbaum and Evans 1997) may not be due to a misspecified pricing equation, but rather to other features of these models (that they share with standard real business cycle models).

Secondly, the result is relevant for the literature on estimation of aggregate supply curves, or various forms of Phillips curves, in that it may redirect both the theoretical and empirical effort towards understanding the determinants of marginal costs and the relationship between marginal cost and output, rather than to further experimentation with alternative models of price adjustment. If one believes the results of this paper, to explain price behavior one should not necessarily look for other shocks (like energy price shock, for example), that alter the price-labor cost relationship, nor postulate additional stickiness in the inflation rate (as 
opposed to the price level), as in the FRB-US model (see Brayton and Tinsley, 1996) and the model of Furher and Moore (1995). What one should look for, instead, is an empirically successful model to explain the behavior of the unit labor costs.

\section{Appendix}

\subsection{Model with costs of adjusting prices}

\subsubsection{Evaluate the first order condition for the firm's optimal pricing decision}

From the technology, $H_{i t}$ can be expressed as a function of prices:

$$
H_{i t}=Z_{t}^{-1}\left(Y_{i t} / K_{i t}^{a}\right)^{\frac{1}{1-a}}=Z_{t}^{-1}\left[\left(P_{i t} / P_{t}\right)^{-\theta} Y_{t} / K_{i t}^{a}\right]^{\frac{1}{1-a}}
$$

From the demand of good $i$ :

$$
\partial Y_{i t} / \partial P_{i t}=-\theta\left(P_{i t} / P_{t}\right)^{-\theta-1} Y_{t} / P_{t}=-\theta\left(Y_{i t} / P_{i t}\right)
$$

so that

$$
\partial H_{i t} / \partial P_{i t}=-[\theta /(1-a)]\left(H_{i t} / P_{i t}\right)
$$

Using (6.2) and (6.3), the partial derivative of profits at time $t$ is:

$$
\begin{aligned}
\partial \Pi_{i t} / \partial P_{i t} & =Y_{i t}+P_{i t}\left(\partial Y_{i t} / \partial P_{i t}\right)-W_{t}\left(\partial H_{i t} / \partial P_{i t}\right)-\frac{P_{t} Y_{t}}{P_{i t}} \phi^{\prime}\left(\ln \frac{P_{i t}}{P_{i t-1}}\right) \\
& =(1-\theta) Y_{i t}+\frac{\theta}{1-a} \frac{W_{t} H_{i t}}{P_{i t}}-\frac{P_{t} Y_{t}}{P_{i t}} \phi^{\prime}\left(\ln \frac{P_{i t}}{P_{i t-1}}\right)
\end{aligned}
$$

and

$$
\partial \Pi_{i t+1} / \partial P_{i t}=\frac{P_{t+1} Y_{t+1}}{P_{i t}} \phi^{\prime}\left(\ln \frac{P_{i t+1}}{P_{i t}}\right)
$$

The first order condition for the optimal choice of $P_{i t}, \partial \Pi_{t} / P_{i t}+E_{t} R_{t, t+1} \partial \Pi_{t+1} / P_{i t}=0$, is then:

$$
(1-\theta)+\frac{\theta}{1-a} \frac{W_{t} H_{i t}}{P_{i t} Y_{i t}}-\frac{P_{t} Y_{t}}{P_{i t} Y_{i t}} \phi^{\prime}\left(\ln \frac{P_{i t}}{P_{i t-1}}\right)+E_{t} R_{t, t+1} \frac{P_{t+1} Y_{t+1}}{P_{i t} Y_{i t}} \phi^{\prime}\left(\ln \frac{P_{i t+1}}{P_{i t}}\right)=0
$$

where I divided the whole expression by $Y_{i t}$. Rearranging:

$$
\frac{1}{1-a} \frac{W_{t} /\left(Y_{i t} / H_{i t}\right)}{P_{i t}}=\frac{1}{\theta}\left[(\theta-1)+\frac{P_{t} Y_{t}}{P_{i t} Y_{i t}} \phi^{\prime}\left(\ln \frac{P_{i t}}{P_{i t-1}}\right)-E_{t} R_{t, t+1} \frac{P_{t+1} Y_{t+1}}{P_{i t} Y_{i t}} \phi^{\prime}\left(\ln \frac{P_{i t+1}}{P_{i t}}\right)\right]
$$

Evaluating this expression at a symmetric equilibrium (where $Y_{i t}=Y_{t}, H_{i t}=H_{t}$ and $\left.P_{i t}=P_{t}\right)$ :

$$
\frac{1}{1-a} \frac{W_{t} /\left(Y_{t} / H_{t}\right)}{P_{t}}=\frac{1}{\theta}\left[(\theta-1)+\phi^{\prime}\left(\ln \pi_{t}\right)-E_{t} R_{t, t+1} \pi_{t+1} \gamma_{y t+1} \phi^{\prime}\left(\ln \pi_{t+1}\right)\right]
$$

Denoting the right hand side expression by $\frac{1}{\mu_{t}}$, we get expression (3.4) in the text. 


\subsubsection{Evaluate $\widehat{\mu}_{t}$}

$$
\widehat{\mu}_{t}=-\frac{1}{\theta-1}\left[\phi^{\prime \prime}(0) \widehat{\pi}_{t}-\left(\phi^{\prime \prime}(0) \gamma_{y}^{*}+\phi^{\prime}(0)\right) R E_{t} \widehat{\pi}_{t+1}-\gamma_{y}^{*} \phi^{\prime}(0) R E_{t} \widehat{\gamma}_{y t+1}\right]
$$

By assumption, $\phi(0)=\phi^{\prime}(0)=0$, and therefore:

$$
\begin{aligned}
\widehat{\mu}_{t} & =-\frac{1}{\theta-1}\left(\phi^{\prime \prime}(0) \widehat{\pi}_{t}-\phi^{\prime \prime}(0) \gamma_{y}^{*} R E_{t} \widehat{\pi}_{t+1}\right) \\
& =-\frac{\phi^{\prime \prime}(0)}{\theta-1}\left(\widehat{\pi}_{t}-\gamma_{y}^{*} R E_{t} \widehat{\pi}_{t+1}\right)
\end{aligned}
$$

Setting $\alpha_{0}=\frac{\phi^{\prime \prime}(0)}{\theta-1}$ and $\alpha_{1}=\gamma_{y}^{*} R$, this expression gives (3.7) in the text.

\subsubsection{Solving for the optimal path of prices}

Start from eq.(3.7) in the text, which is

$$
\widehat{\mu}_{t}=-\alpha_{0}\left[\widehat{\pi}_{t}-\alpha_{1} E_{t} \widehat{\pi}_{t+1}\right]
$$

By definition, $\widehat{\mu}_{t}=\ln \mu_{t}-\ln \mu^{*}=\ln \mu_{t}-\ln (\theta /(\theta-1))$, so eq.(6.4) becomes:

$$
\begin{aligned}
\ln \mu_{t}-\ln (\theta /(\theta-1)) & =-\alpha_{0}\left[\widehat{\pi}_{t}-\alpha_{1} E_{t} \widehat{\pi}_{t+1}\right] \\
& =-\alpha_{0}\left[\Delta p_{t}-\alpha_{1} E_{t} \Delta p_{t+1}\right]
\end{aligned}
$$

Substitute $\ln \mu_{t}$ from eq (3.5) in the text, and use lowercase letters for logs:

$$
\ln (\theta /(1-a))+u l c_{t}-p_{t}-\ln (\theta-1)=\alpha_{0}\left[\Delta p_{t}-\alpha_{1} E_{t} \Delta p_{t+1}\right]
$$

Rearranging

$$
u l c_{t}-p_{t}=\kappa+\alpha_{0}\left[\Delta p_{t}-\alpha_{1} E_{t} \Delta p_{t+1}\right]
$$

where $\kappa=\ln [(1-a)(\theta-1) / \theta]$.

Explicitely writing the price differences:

$$
\begin{aligned}
u l c_{t} & =\kappa+\left[\left(1+\alpha_{0}\right)+\alpha_{0} \alpha_{1}\right] p_{t}-\alpha_{0} p_{t-1}-\alpha_{0} \alpha_{1} E_{t} p_{t+1} \\
& =\kappa-\alpha_{0} \alpha_{1} E_{t}\left[1-\frac{1+\alpha_{1}+\alpha_{0}^{-1}}{\alpha_{1}} L+\frac{1}{\alpha_{1}} L^{2}\right] p_{t+1} \\
& =\kappa-\alpha_{0} \alpha_{1} E_{t}\left[L^{2} P\left(L^{-1}\right)\right] p_{t+1} \\
& =\kappa-\alpha_{0} \alpha_{1} E_{t}\left(1-\lambda_{1} L\right)\left(1-\lambda_{2} L\right) p_{t+1}
\end{aligned}
$$

where the assumptions $\alpha_{0}>0$ and $0<\alpha_{1} \leq 1$ imply that the two roots of the polynomial $\mathrm{P}(\lambda)=0$ are real $\lambda_{1}, \lambda_{2}$ satisfying $0<\lambda_{1}<1$, and $\lambda_{2}>\alpha_{1}^{-1} \geq 1$. 
Defining $x_{t+1}=\left(1-\lambda_{1} L\right) p_{t+1}$, rewrite $u l c_{t}$ as

$$
\begin{aligned}
u l c_{t} & =\kappa-\alpha_{0} \alpha_{1} E_{t}\left(1-\lambda_{2} L\right) x_{t+1} \\
& =\kappa-\alpha_{0} \alpha_{1}\left(E_{t} x_{t+1}-\lambda_{2} x_{t}\right) \\
& =\kappa+\left(\alpha_{0} \alpha_{1} \lambda_{2}\right) x_{t}-\alpha_{0} \alpha_{1} E_{t} x_{t+1}
\end{aligned}
$$

from which

$$
x_{t}=\left(\alpha_{0} \alpha_{1} \lambda_{2}\right)^{-1}\left(u l c_{t}-\kappa\right)+\lambda_{2}^{-1} E_{t} x_{t+1}
$$

Solving forward

$$
\begin{aligned}
x_{t} & =\left(\alpha_{0} \alpha_{1} \lambda_{2}\right)^{-1} \sum_{j=0}^{\infty} \lambda_{2}^{-j} E_{t}\left(u l c_{t+j}-\kappa\right) \\
& =\left(1-\lambda_{1}\right)\left(1-\lambda_{2}^{-1}\right) \sum_{j=0}^{\infty} \lambda_{2}^{-j} E_{t}\left(u l c_{t+j}-\kappa\right)
\end{aligned}
$$

where the equality $\left(\alpha_{0} \alpha_{1} \lambda_{2}\right)^{-1}=\left(1-\lambda_{1}\right)\left(1-\lambda_{2}^{-1}\right)$ follows from the fact that $\left(\lambda_{1}+\lambda_{2}\right)=$ $\frac{1+\alpha_{1}+\alpha_{0}^{-1}}{\alpha_{1}}$ and $\lambda_{1} \lambda_{2}=1 / \alpha_{1}$. Finally, from the definition of $x_{t}$, obtain

$$
p_{t}=\lambda_{1} p_{t-1}+\left(1-\lambda_{1}\right)\left\{\left(1-\lambda_{2}^{-1}\right) \sum_{j=0}^{\infty} \lambda_{2}^{-j} E_{t}\left(u l c_{t+j}-\kappa\right)\right\}
$$

which is expression (3.9) in the text.

\subsubsection{Computation of the theoretical price path}

Because the estimated VAR delivers forecast of the rate of change of the unit labor cost, $\Delta u l c_{t+j}$, the actual equation used to compute the theoretical price path is a transformation of eq.(3.10). Using the fact that

$$
E_{t} \sum_{j=0}^{\infty} \lambda_{2}^{-j} u l c_{t+j}=\frac{1}{\left(1-\lambda_{2}^{-1}\right)}\left(u l c_{t}+E_{t} \sum_{j=0}^{\infty} \lambda_{2}^{-j} \Delta u l c_{t+j}\right)
$$

eq. (3.9) becomes

$$
p_{t}=\lambda_{1} p_{t-1}+\left(1-\lambda_{1}\right) u l c_{t}+\left(1-\lambda_{1}\right) \sum_{j=0}^{\infty} \lambda_{2}^{-j} E_{t}\left(\Delta u l c_{t+j}\right)-\left(1-\lambda_{1}\right) \kappa
$$

which can be written as

$$
p_{t}-u l c_{t}=\lambda_{1}\left(p_{t-1}-u l c_{t-1}\right)-\Delta u l c_{t}+\left(1-\lambda_{1}\right) \sum_{j=0}^{\infty} \lambda_{2}^{-j} E_{t}\left(\Delta u l c_{t+j}\right)-\left(1-\lambda_{1}\right) \kappa
$$

I therefore directly compute theoretical $\mathrm{p} / \mathrm{ulc}$ ratios according to this equation (ignoring the constant term, because I want to compute deviation from the mean): For each value of the parameters $\alpha_{0}$ and $\alpha_{1}$ in a chosen grid, I solve for the roots $\lambda_{1}$ and $\lambda_{2}$, and compute the forecast $\sum_{j=0}^{\infty} \lambda_{2}^{-j} E_{t}\left(\Delta u l c_{t+j}\right)$. Because the unity labor cost growth is the first element of the vector $Z_{t}=\Gamma Z_{t-1}+\varepsilon_{z t}$, and $E_{t} Z_{t+j}=\Gamma^{j} Z_{t}$, the weighted sum of unity labor cost forecast into the future is the first element of the vector $\left[I-\lambda_{2}^{-1} \Gamma\right]^{-1} Z_{t}$. 


\subsection{Model with random probability of changing prices}

Substituting (3.19) into (3.17) get

$$
\widehat{x}_{t}=\left(1-\alpha R \gamma_{y}^{*}\right) \Sigma_{j=0}^{\infty}\left(\alpha R \gamma_{y}^{*}\right)^{j} E_{t}\left(\widehat{s}_{t+j}^{a v g}-\frac{\theta a}{1-a}\left(\widehat{x}_{t}-\Sigma_{k=1}^{j} \widehat{\pi}_{t+k}\right)+\Sigma_{k=1}^{j} \widehat{\pi}_{t+k}\right)
$$

or

$$
\widehat{x}_{t}=\frac{\left(1-\alpha R \gamma_{y}^{*}\right)(1-a)}{(1-a+a \theta)} \Sigma_{j=0}^{\infty}\left(\alpha R \gamma_{y}^{*}\right)^{j} E_{t}\left(\widehat{s}_{t+j}^{a v g}+\frac{1-a+a \theta}{1-a} \Sigma_{k=1}^{j} \widehat{\pi}_{t+k}\right)
$$

Let $\xi \equiv \frac{1-a}{1-a+a \theta}$. Then, using (3.16), get

$$
\widehat{\pi}_{t}=\left(\frac{(1-\alpha)\left(1-\alpha R \gamma_{y}^{*}\right) \xi}{\alpha}\right) \Sigma_{j=0}^{\infty}\left(\alpha R \gamma_{y}^{*}\right)^{j} E_{t}\left(\widehat{s}_{t+j}^{a v g}+\frac{1}{\xi} \Sigma_{k=1}^{j} \widehat{\pi}_{t+k}\right)
$$

Now evaluate this expression at $t+1$, premultiply it by $\alpha R \gamma_{y}^{*}$, take its expected value as of time $t$, and subtract it from the above to get:

$$
\widehat{\pi}_{t}-\alpha R \gamma_{y}^{*} E_{t} \widehat{\pi}_{t+1}=\left(\frac{(1-\alpha)\left(1-\alpha R \gamma_{y}^{*}\right) \xi}{\alpha}\right) J_{t}
$$

where

$$
\begin{aligned}
J_{t} & =\Sigma_{j=0}^{\infty}\left(\alpha R \gamma_{y}^{*}\right)^{j} E_{t}\left(\widehat{s}_{t+j}^{a v g}+\frac{1}{\xi} \Sigma_{k=1}^{j} \widehat{\pi}_{t+k}\right)-\Sigma_{j=0}^{\infty}\left(\alpha R \gamma_{y}^{*}\right)^{j+1} E_{t}\left(\widehat{s}_{t+j+1}^{a v g}+\frac{1}{\xi} \Sigma_{k=1}^{j} \widehat{\pi}_{t+k+1}\right) \\
& =\Sigma_{j=0}^{\infty}\left(\alpha R \gamma_{y}^{*}\right)^{j} E_{t}\left\{\left[\widehat{s}_{t+j}^{a v g}-\alpha R \gamma_{y}^{*} \widehat{s}_{t+j+1}^{a v g}\right]+\frac{1}{\xi} \Sigma_{k=1}^{j}\left[\widehat{\pi}_{t+k}-\alpha R \gamma_{y}^{*} \widehat{\pi}_{t+k+1}\right]\right\} \\
& =\widehat{s}_{t}^{a v g}+\frac{\alpha R \gamma_{y}^{*}}{\xi}\left(\frac{1}{1-\alpha R \gamma_{y}^{*}} E_{t} \widehat{\pi}_{t+1}\right)
\end{aligned}
$$

Expression (6.6) becomes therefore

$$
\widehat{\pi}_{t}=\left(\frac{(1-\alpha)\left(1-\alpha R \gamma_{y}^{*}\right) \xi}{\alpha}\right) \widehat{s}_{t}^{a v g}+R \gamma_{y}^{*} E_{t} \widehat{\pi}_{t+1}
$$

which is eq. (3.20) in the text.

\section{References}

1. Bils, Mark (1987) "The Cyclical Behavior of Marginal Cost and Price" American Economic Review, vol. 77, pp.838-857.

2. Blanchard, Olivier (1997) "The Medium Run", forthcoming in Brookings Papers on Economic Activity. 
3. Blinder, Alan S., Elie R.D. Canetti, David Lebow and Jeremy B. Rudd (1998) Asking About Prices: A New Approach to Understand Price Stickiness, New York: Russell Sage Foundation.

4. Brayton, F. and P.A. Tinsley (1996) "A Guide to FRB/US: A Macroeconomic Model of the United States", Federal Reserve Board, Finance and Economic Discussion Series 1996-42.

5. Calvo, Guillermo A. (1983) "Staggered Prices in a Utility -Maximizing Framework", Journal of Monetary Economics, 12, pp. 983-998.

6. Christiano, Lawrence J., Martin Eichenbaum and Charles L. Evans (1997) "Sticky Price and Limited Participation Models of Money: A Comparison", European Economic Review, 41 (6), pp. 1201-1249.

7. Diebold, Francis X., Lee E. Ohanian and Jeremy Berkowitz (1995) "Dynamic Equilibrium Economies: A Framework for Comparing Models and Data", unpublished.

8. Eckstein, Otto and Gary Fromm (1968) "The Price Equation", American Economic Review, vol LVIII, pp.1159-1183.

9. Fuhrer, Jeffrey C. (1997) "The (Un)Importance of Forward-Looking Behavior in Price Specification" Journal of Money, Credit and Banking, vol. 29, 3, pp. 338-350.

10. — and George Moore (1995) "Inflation Persistence", Quarterly Journal of Economics, vol. CX (1), pp.127-159.

11. Gali', Jordi and Mark Gertler (1998) "Inflation Dynamics: A Structural Econometric Analysis", unpublished.

12. Goodfriend, Marvin and Robert G. King (1997) "The New Neoclassical Synthesis and the Role of Monetary Policy", NBER Macroeconomics Annual, pp. 231-283.

13. Ireland, Peter (1996) "A Small, Structural, Quarterly Model for Monetary Policy Evaluation", forthcoming in Carnegie-Rochester Conference Series on Public Policy.

14. King, Robert G. and Mark W. Watson (1996) "Money, Prices, Interest Rates and the Business Cycle", The Review of Economics and Statistics, pp. 35-53.

15. Lucas, R.E.,Jr. (1976) "Econometric Policy Evaluation: A Critique", Carnegie-Rochester Conference Series on Public Policy, 1, pp.19-46.

16. Phelps, Edmund S. and Sidney G.Winter (1970) "Optimap Price Policy under Atomistic Competition", in E.Phelps (ed.) Microeconomic Foundations of Employment and Inflation Theory, W.W. Norton and Co., New York. 
17. Roberts, John M. (1995) "New Keynesian Economics and the Phillips Curve", Journal of Money, Credit and Banking 27, pp. 975-984.

18. _ _ (1997) "Is Inflation Sticky?", Journal of Monetary Economics, 39, (2), pp.173-196.

19. _ (1998) "Inflation Expectations and the Transmission of Monetary Policy", unpublished.

20. — David J. Stockton and Charles S. Struckmeyer (1994) "Evidence on the Flexibility of Prices", Review of Economics and Statistics, pp. 142-150.

21. Rotemberg, Julio J. (1982) "Sticky Prices in the United States", Journal of Political Economy, 90, pp. 1187-1211.

22. - (1987) "The New Keynesian Microfoundations", NBER Macroeconomics Annual, pp.69-104.

23. - (1995) "Price, Output and Hours: An Empirical Analysis Based on a Sticky Price Model" Journal of Monetary Economics, 37, (3), pp.505-533.

24. — and Michael Woodford (1991) "Markups and the Business Cycle", NBER Macroeconomics Annual, pp. 63-129.

25. — and — (1992) "Oligopolistic Pricing and the Effects of Aggregate Demand on Economic Activity", Journal of Political Economy, 100, n.6, pp. 1153-1207.

26. — and - (1997) "An Optimization-Based Econometric Framework for the Evaluation of Monetary Policy", NBER Macroeconomics Annual, pp. 297-346.

27. — and (1998) "The Cyclical Behavior of Prices and Costs", forthcoming in Handbook of Macroeconomics, edited by John B. Taylor and Michael Woodford.

28. Sbordone, Argia M. (1998) "Prices and Unit Labor Costs: Testing Models of Pricing Behavior", unpublished.

29. Watson, Mark W. (1993) "Measures of Fit for Calibrated Models", Journal of Political Economy, vol. 101, n.6, pp. 1011-1041.

30. Woodford, Michael (1996) "Control of the Public Debt: A Requirement for Price Stability?" NBER Working Paper n. 5684, July.

31. Yun, Tack (1996) "Nominal Price Rigidity, Money Supply Endogeneity, and Business Cycles", Journal of Monetary Economics, 37, (2), pp.345-370. 

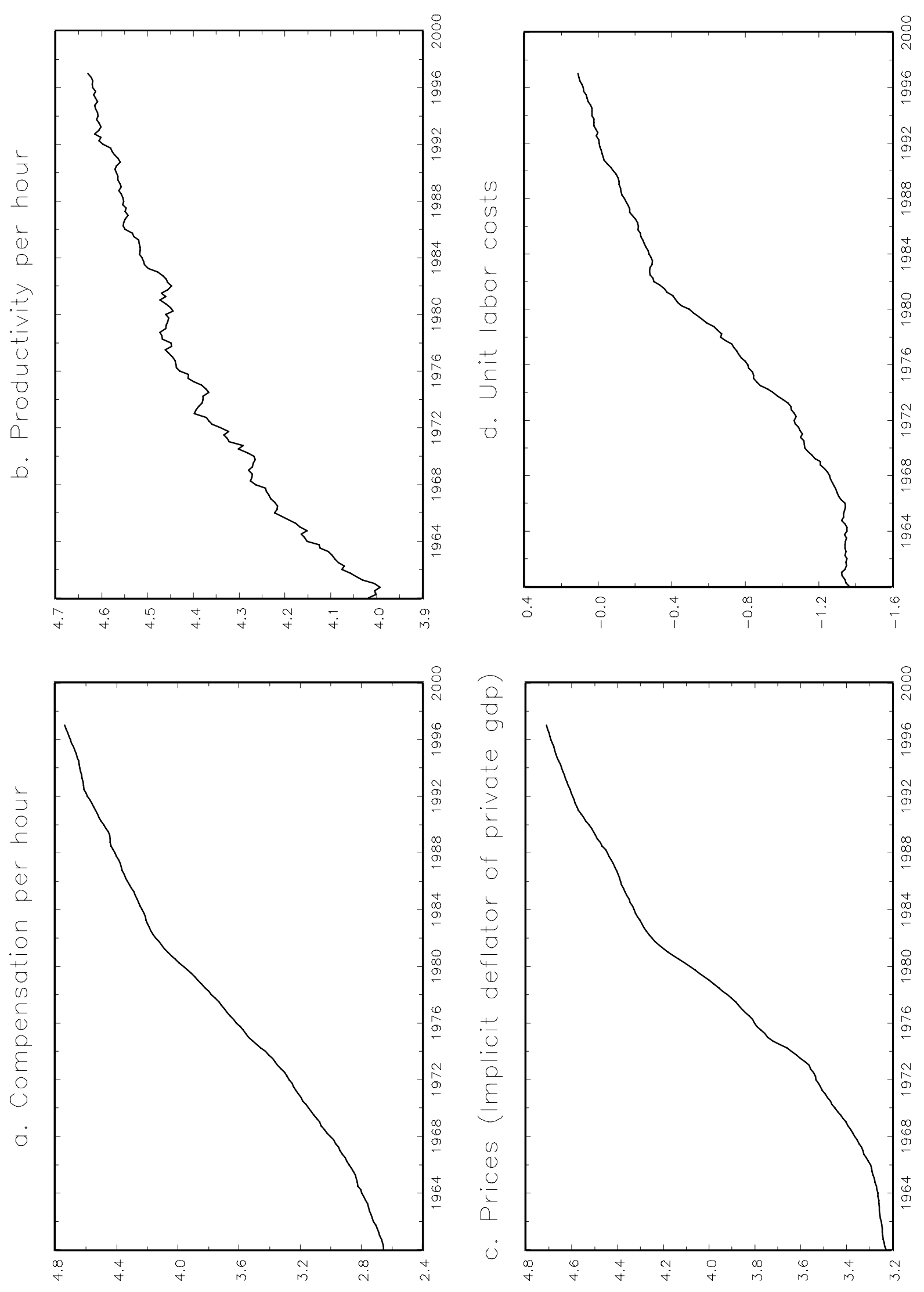
FIGURE 2

a. Price/ulc ratio, benchmark model vs. data

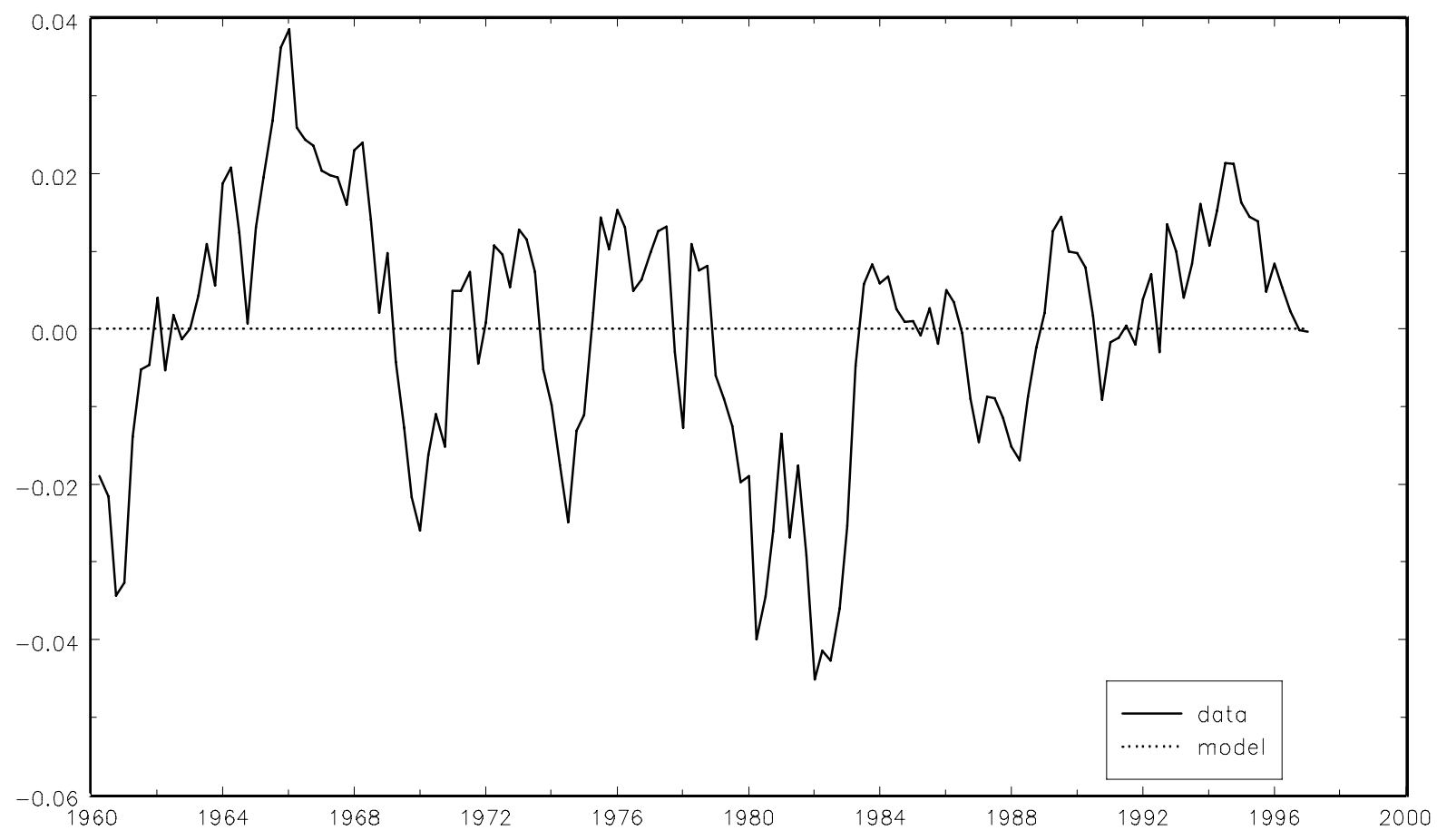

b. Inflation, benchmark model vs data

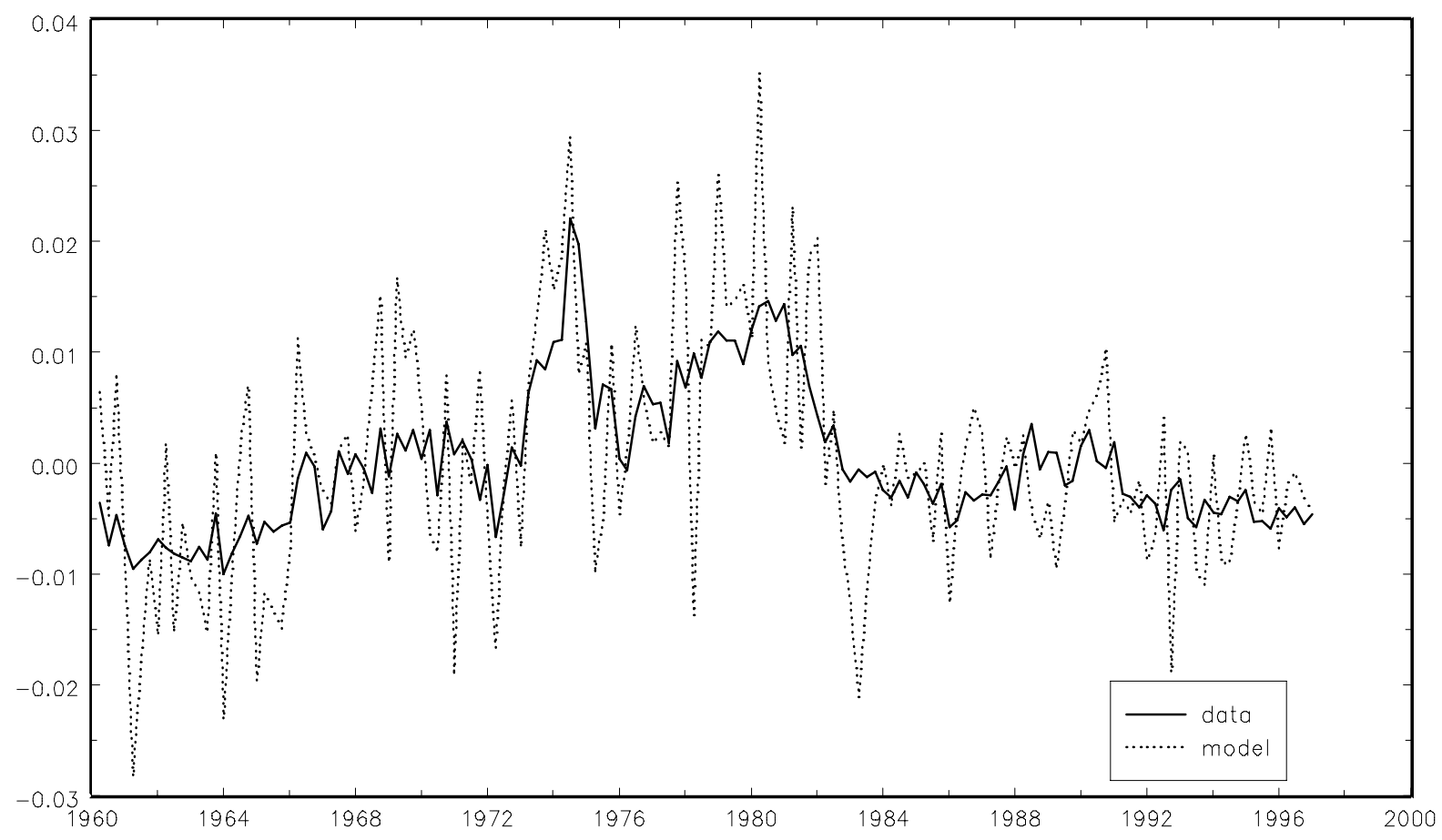




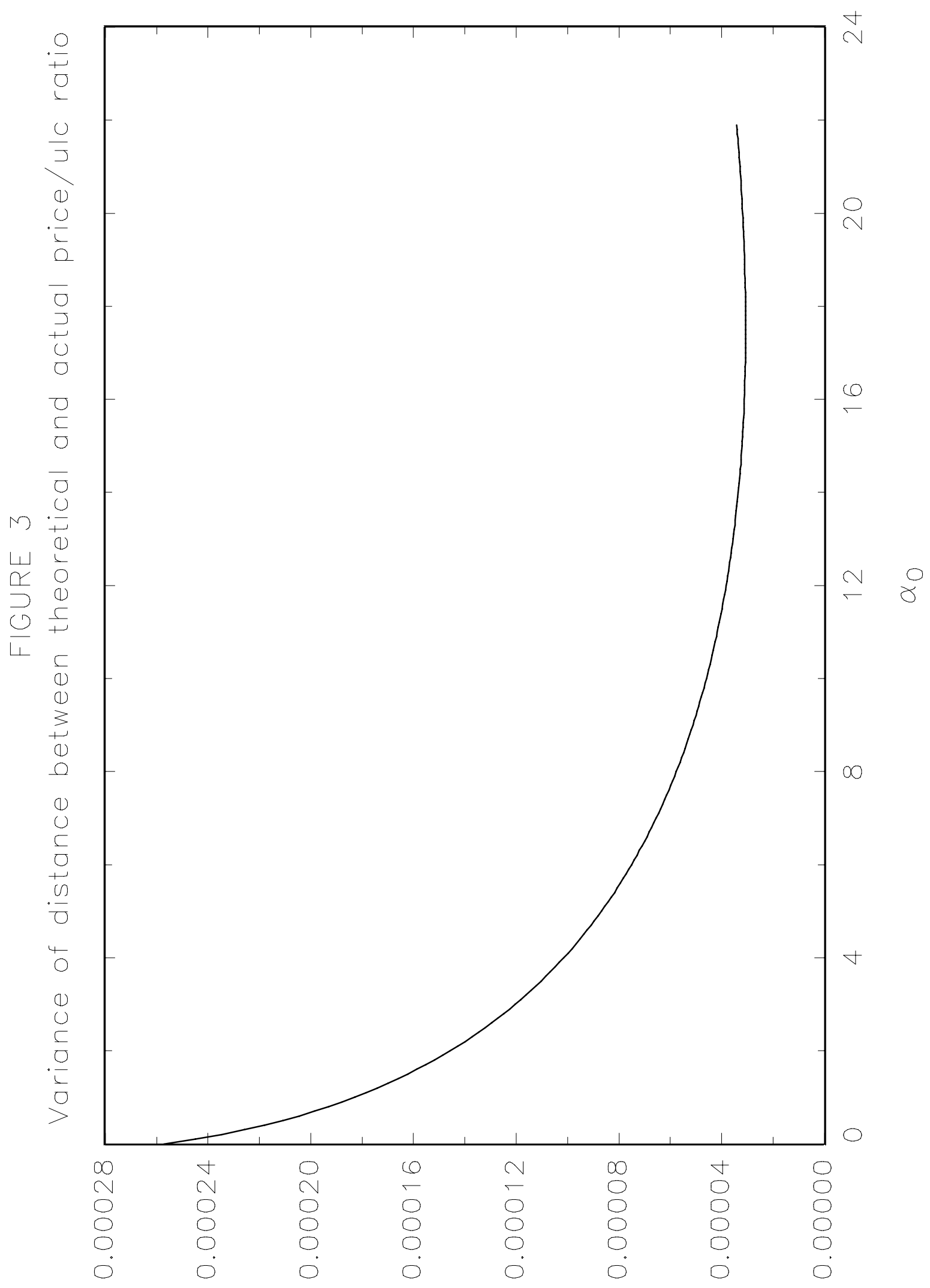




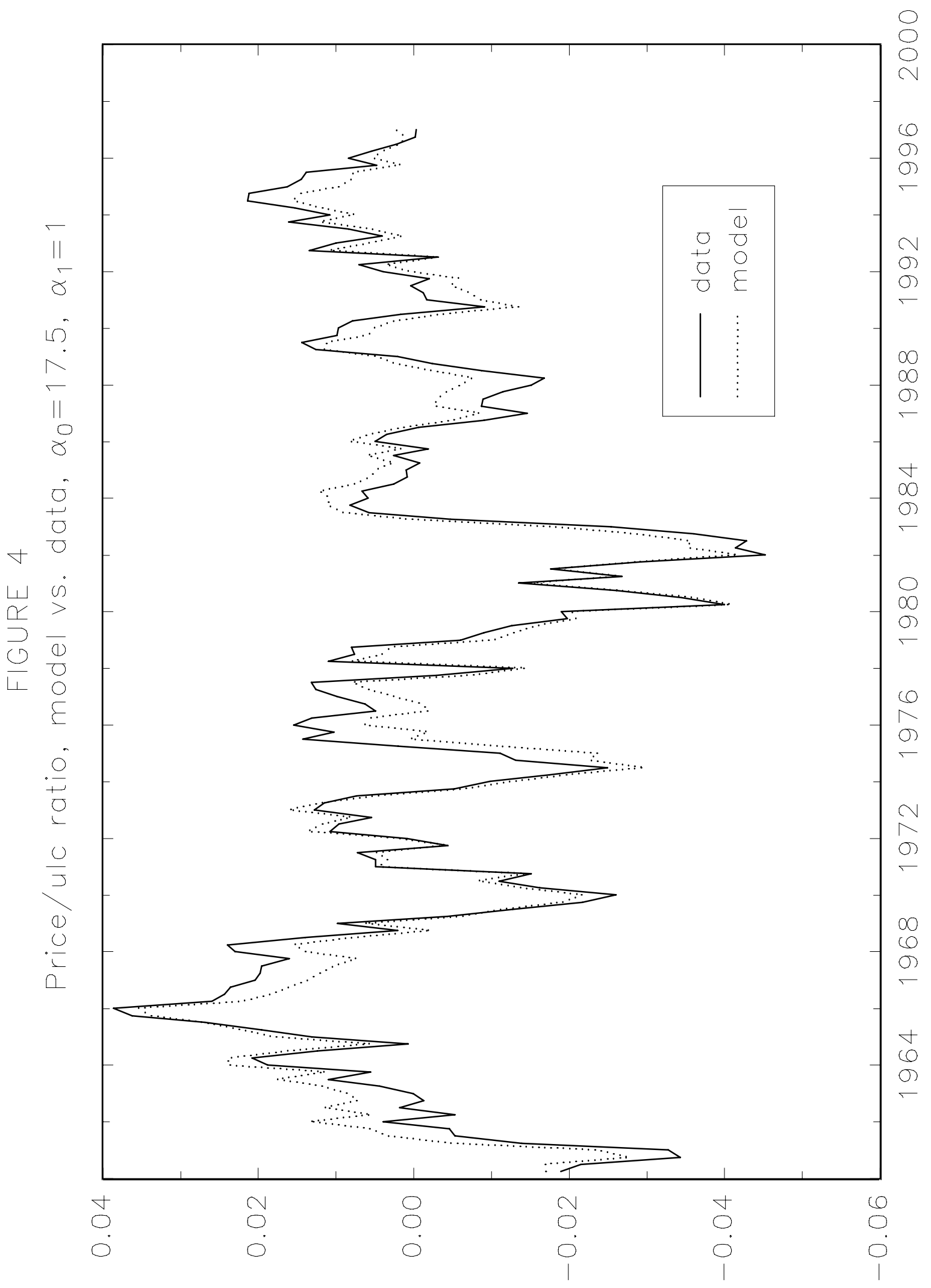




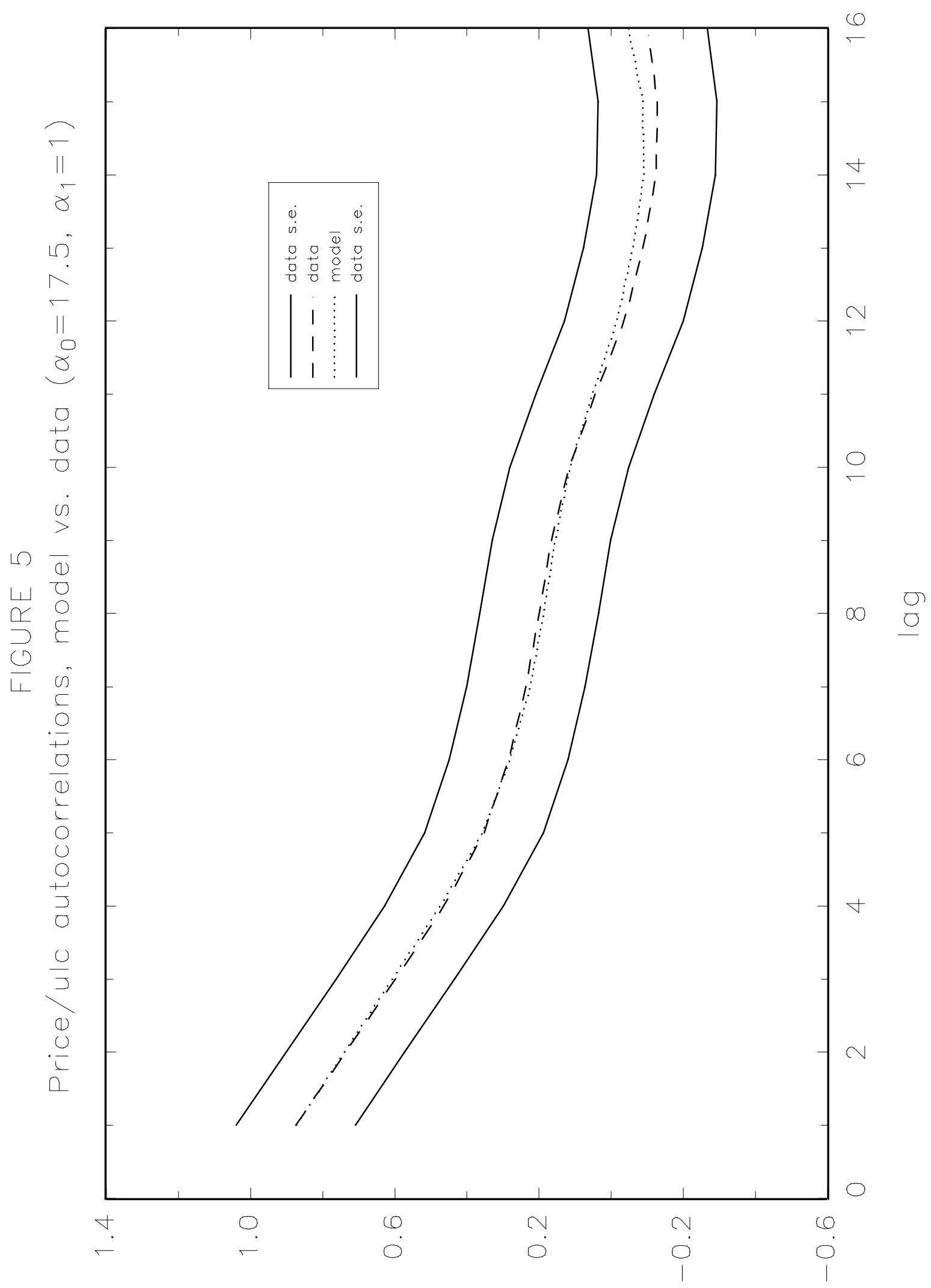




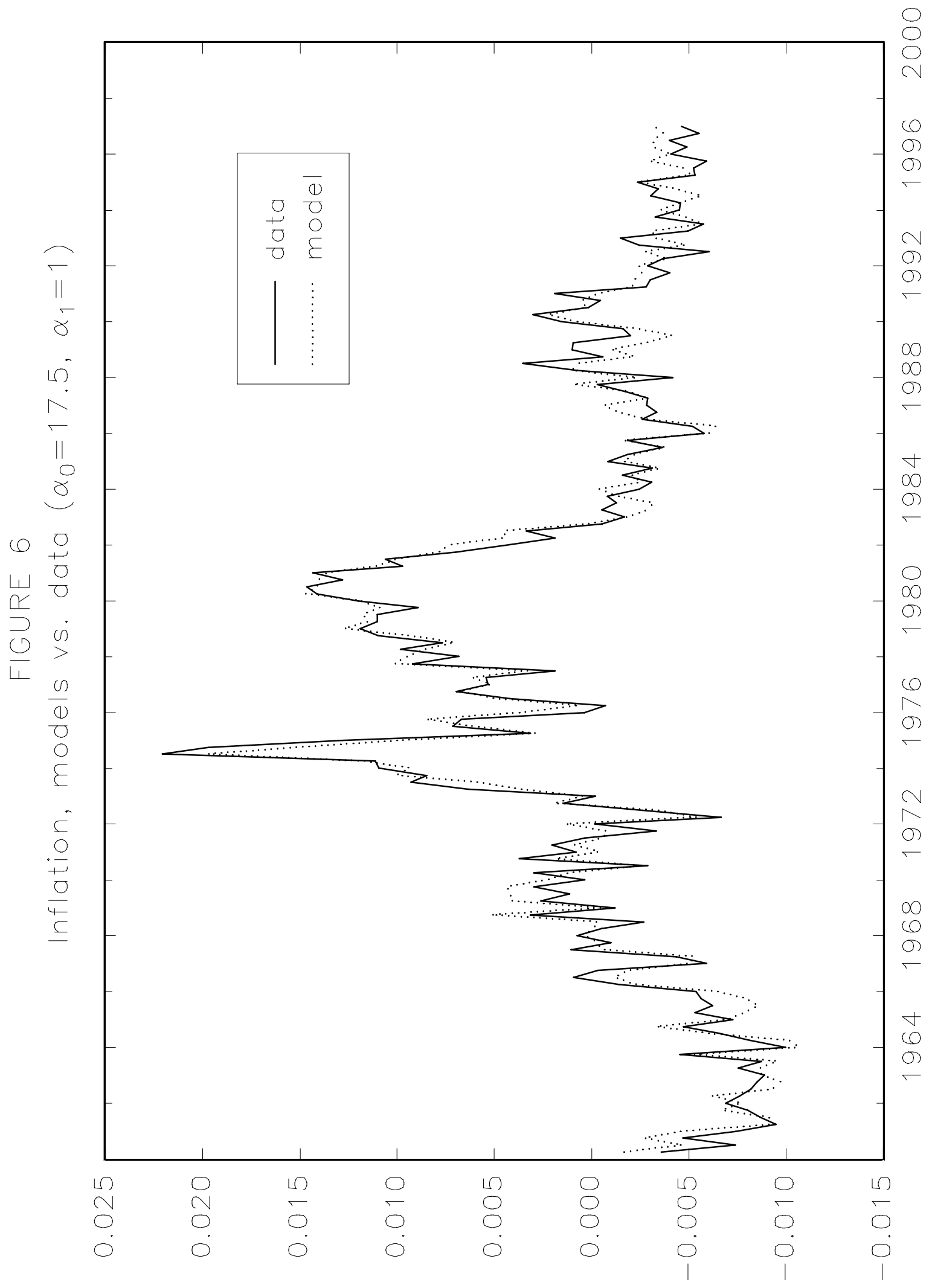




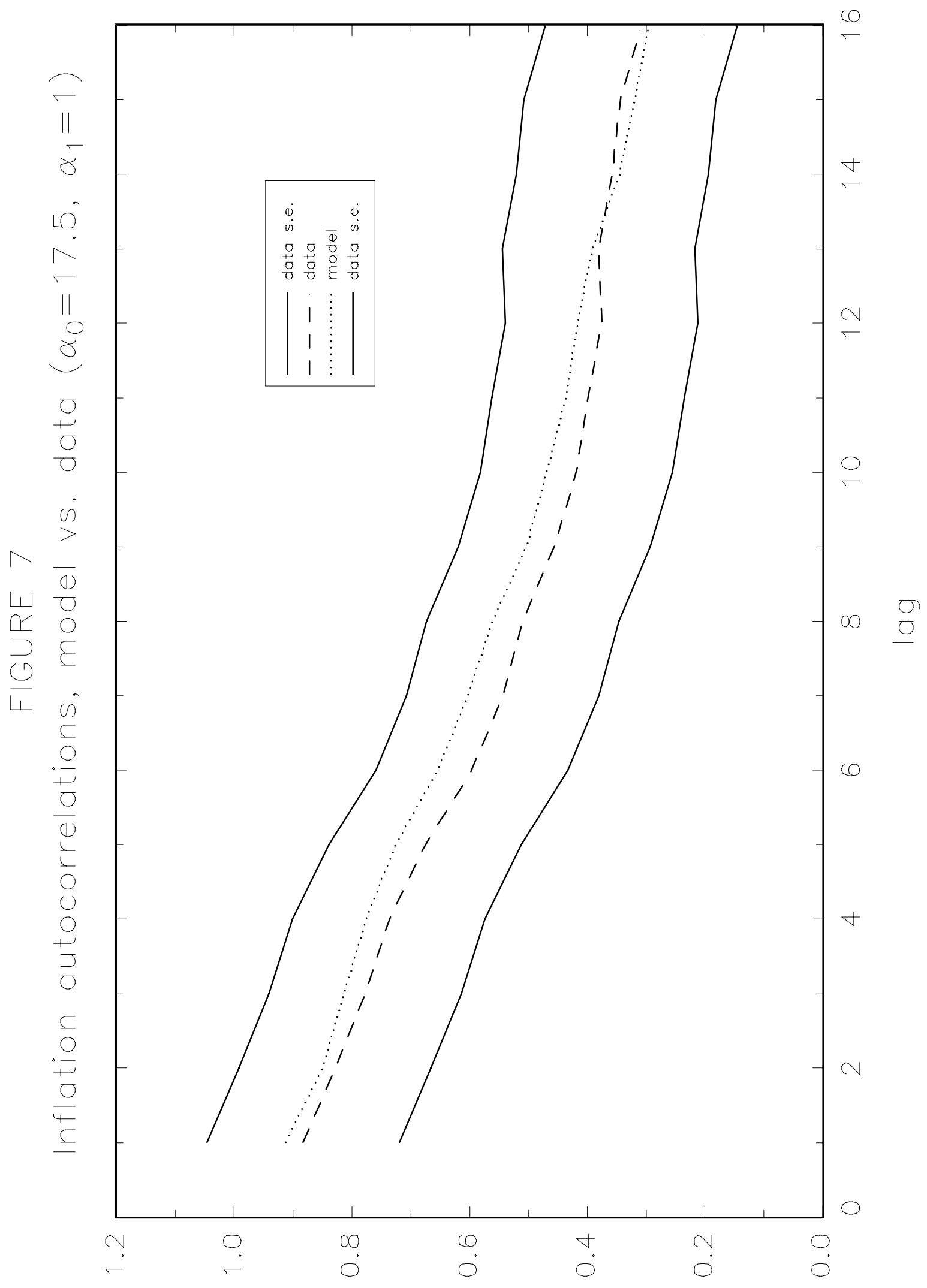




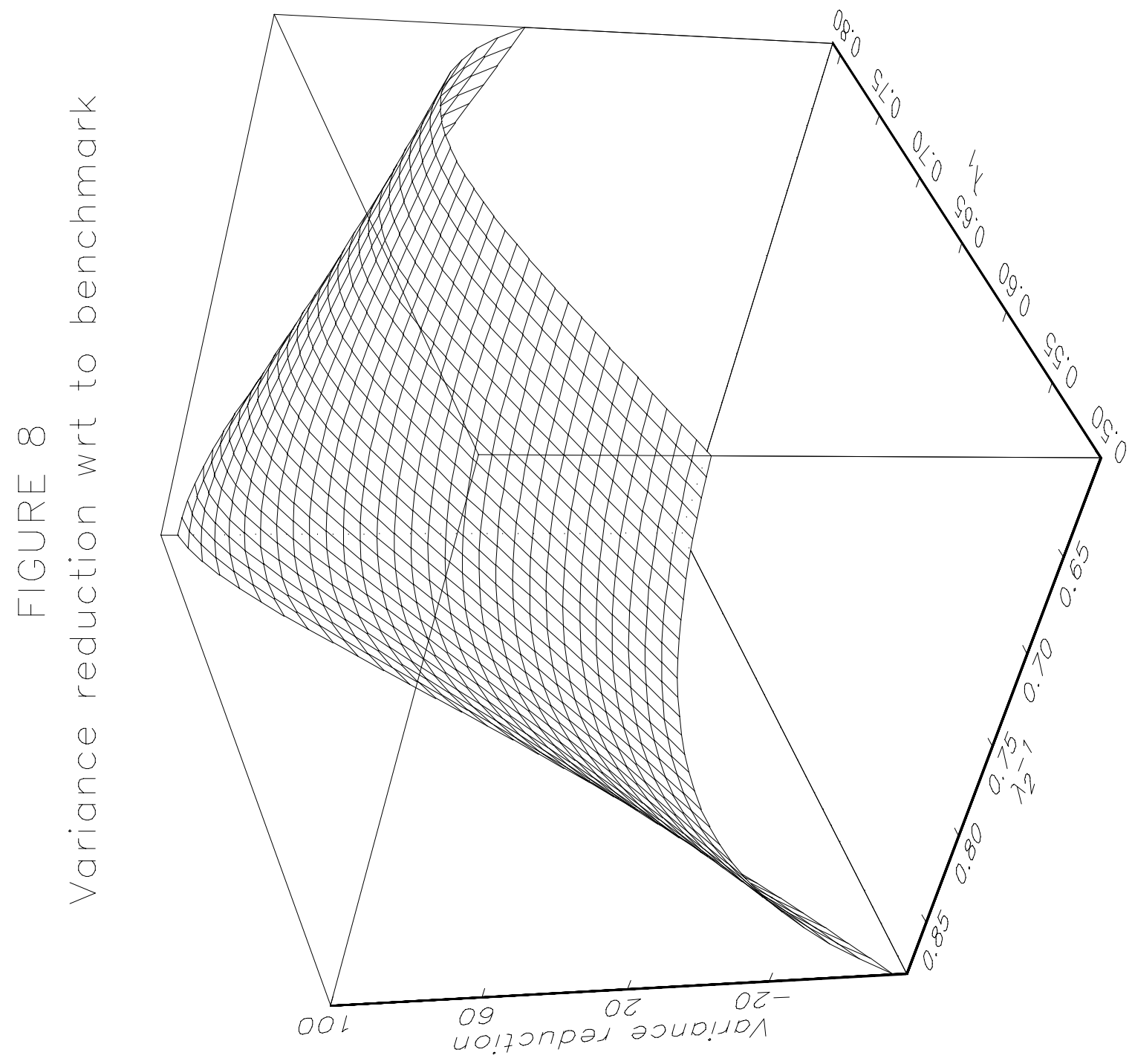

